\title{
Integrative pathway dissection of molecular mechanisms of moxLDL-induced vascular smooth muscle phenotype transformation
}

\author{
George S Karagiannis ${ }^{1,2}$, Jochen Weile ${ }^{3}$, Gary D Bader ${ }^{3,4}$ and Joe Minta ${ }^{1 *}$
}

\begin{abstract}
Background: Atherosclerosis (AT) is a chronic inflammatory disease characterized by the accumulation of inflammatory cells, lipoproteins and fibrous tissue in the walls of arteries. AT is the primary cause of heart attacks and stroke and is the leading cause of death in Western countries. To date, the pathogenesis of AT is not well-defined. Studies have shown that the dedifferentiation of contractile and quiescent vascular smooth muscle cells $(S M C)$ to the proliferative, migratory and synthetic phenotype in the intima is pivotal for the onset and progression of AT. To further delineate the mechanisms underlying the pathogenesis of AT, we analyzed the early molecular pathways and networks involved in the SMC phenotype transformation.
\end{abstract}

Methods: Quiescent human coronary artery SMCs were treated with minimally-oxidized LDL (moxLDL), for 3 hours and 21 hours, respectively. Transcriptomic data was generated for both time-points using microarrays and was subjected to pathway analysis using Gene Set Enrichment Analysis, GeneMANIA and Ingenuity software tools. Gene expression heat maps and pathways enriched in differentially expressed genes were compared to identify functional biological themes to elucidate early and late molecular mechanisms of moxLDL-induced SMC dedifferentiation.

Results: Differentially expressed genes were found to be enriched in cholesterol biosynthesis, inflammatory cytokines, chemokines, growth factors, cell cycle control and myogenic contraction themes. These pathways are consistent with inflammatory responses, cell proliferation, migration and ECM production, which are characteristic of SMC dedifferentiation. Furthermore, up-regulation of cholesterol synthesis and dysregulation of cholesterol metabolism was observed in moxLDL-induced SMC. These observations are consistent with the accumulation of cholesterol and oxidized cholesterol esters, which induce proinflammatory reactions during atherogenesis. Our data implicate for the first time IL12, IFN-a, HGF, CSF3, and VEGF signaling in SMC phenotype transformation. GPCR signaling, HBP1 (repressor of cyclin D1 and CDKN1B), and ID2 and ZEB1 transcriptional regulators were also found to have important roles in SMC dedifferentiation. Several microRNAs were observed to regulate the SMC phenotype transformation via an interaction with IFN- $\gamma$ pathway. Also, several "nexus" genes in complex networks, including components of the multi-subunit enzyme complex involved in the terminal stages of cholesterol synthesis, microRNAs (miR-203, miR-511, miR-590-3p, miR-346*/miR- 1207-5p/miR-4763-3p), GPCR proteins (GPR1, GPR64, GPRC5A, GPR171, GPR176, GPR32, GPR25, GPR124) and signal transduction pathways, were found to be regulated.

Conclusions: The systems biology analysis of the in vitro model of moxLDL-induced VSMC phenotype transformation was associated with the regulation of several genes not previously implicated in SMC phenotype transformation. The identification of these potential candidate genes enable hypothesis generation and in vivo functional experimentation (such as gain and loss-of-function studies) to establish causality with the process of SMC phenotype transformation and atherogenesis.

\footnotetext{
* Correspondence: joe.minta@gmail.com

'Department of Laboratory Medicine and Pathobiology, Faculty of Medicine,

University of Toronto, Toronto, ON M5S 1A8, Canada

Full list of author information is available at the end of the article
} 


\section{Background}

Atherosclerosis (AT) is a chronic inflammatory disease of medium and large arteries characterized by the accumulation of inflammatory cells, lipoproteins and fibrous tissue that lead to the formation of atherosclerotic plaques. It is the primary cause of heart attacks and stroke, and the leading cause of death and disability in developed countries [1-3]. AT is a multifactorial disease with genetic, environmental and lifestyle risk factors. A variety of atherogenic stimuli including hemodynamic shear stress, infections, lipids and proinflammatory cytokines induce endothelial cell dysfunction and permit the migration of mononuclear cells into the subendothelial space. This process is associated with the transformation of quiescent contractile smooth muscle cells (SMCs) to a proliferative and migratory phenotype. As a result of this transformation, SMCs migrate to the neointima where they produce an extracellular matrix that stabilizes the atherosclerotic plaque [4-9]. Lipids deposited in atherosclerotic plaques are derived largely from the lower-density lipoproteins [LDL, LDL-1, VLDL, betaVLDL, and Lp(a)] of the blood [10,11]. 12/15- lipoxygenase and myeloperoxidase have been identified as lipidoxidizing enzymes that are involved in the formation of biologically active oxidized lipids (cholesterol ester hydroperoxides). The accumulation of these oxidized lipids may initiate the proinflammatory activation of macrophages and SMCs in atherosclerotic lesions $[12,13]$. Mildly or minimally oxidized forms of LDL (moxLDL) activate both cell-mediated and humoral immune responses that perpetuate the chronic inflammatory reactions characteristic of atherosclerosis. The accumulation of cholesterol esters in macrophages and macrophage-like cells induce the release of proinflammatory cytokines, chemokines, reactive oxygen radicals, and matrix metalloproteinases [14-16].

Although the majority of foam cells, containing oxidized lipoproteins, in atherosclerotic lesions are derived from macrophages, SMCs also give rise to a significant number of lipid laden cells. SMCs exposed to atherogenic stimuli such as inflammatory cytokines, shear stress, moxLDL or reactive oxygen radicals or lipids [6,17-19] express high levels of a variety of lipid-binding membrane receptors including LDLR, VLDLR, LOX-1, CD36, type I and type II scavenger receptors, and CXCL16/SR-PSOX for cholesterol uptake [20]. Atherogenic cytokines such as IL- $1 \alpha$, TNF- $\alpha$, and MCSF further upregulate the expression of LDLR and VLDLR [21]. The binding of moxLDL to these receptors then results in the accumulation of high levels of cholesterol and cholesteryl esters by the macrophages and SMCs, which then transform into foam cells in early fatty streak lesions. These changes characterize the initiation and progression of atherosclerosis and restenosis [19].
moxLDL has been shown to induce SMC transformation from the "contractile" phenotype to the "migratory, proliferative and synthetic" phenotype, central to intimal hyperplasia and atherogenesis $[4,19]$. Activated SMCs also produce cytokines such as PDGF, TGF- $\beta$ and IFN, which contribute to the initiation and propagation of the inflammatory response of the vessel wall $[18,19,22,23]$.

Recently, a number of investigators have used systematic approaches to investigate atherosclerosis. In these works, biopsies of stable and unstable plaques from symptomatic and asymptomatic patients as well as lesions in mouse models for AT have been examined. Gene expression profiles, pathways and molecular networks were analyzed, that underlie the formation of atherosclerotic plaques [24-31]. As a result, these studies have implicated many potential human atherogenic genes related to lipid homeostasis and have reported changes in the cytokine-induced immune and inflammatory responses as part of the pathogenesis of AT. Such studies have also underscored SMC dedifferentiation as a key process in the initiation and progression of AT.

Despite these advances, the molecular mechanisms of SMC transformation during initiation and progression of atherogenesis are not well-defined. However, the identification of early critical pathways involved in SMC transformation can provide insights into the mechanisms that underlie the pathogenesis of AT and cardiovascular diseases and could deliver potential targets for drug discovery. To facilitate such analyses, we have previously used oligonucleotide microarrays to analyze the genome-wide differential gene expression in quiescent primary human coronary artery SMCs induced with moxLDL for $3 \mathrm{~h}$ and $21 \mathrm{~h}$ [32]. This work uncovered several genes not previously implicated in the moxLDL-induced SMC phenotype transformation and described numerous functional categories of genes with altered gene expression.

Here, we significantly extended the original analysis of the resulting gene expression data using a number of pathway analysis tools - Gene Set Enrichment Analysis (GSEA) [33], Enrichment Map visualization [34], Ingenuity Pathway Analysis (IPA) and GeneMANIA. We found new, non-previously described functional themes and pathways, which may help elucidate the early and late mechanisms of moxLDL-induced SMC phenotype transformation and the onset and progression of atherogenesis. While the in vitro atherogenesis model involving moxLDL treatment of VSMC, particularly in the absence of endothelial cells and immune and inflammatory cells, is an oversimplified model of the complex process of atherogenesis, our systems analysis on the interactions of moxLDL and VSMC has uncovered several novel gene and pathway changes. These observations now permit hypotheses generation and in vivo functional testing (such as gain and loss-of-function studies) to establish 
causality with the process of SMC phenotypic transformation and atherogenesis.

\section{Methods}

\section{Microarray analysis}

The microarray analysis of moxLDL treated cells has been previously described [32]. Briefly, human coronary artery SMCs were purchased from Clonetics (Walkersville, MD) and cultured according to the manufacturer's instructions and used between passages 4-7. Confluent SMC cultures were synchronized to quiescence by incubation for $48 \mathrm{~h}$ in basal medium (SmBM) containing 0.5\% FBS. The cells were then washed and incubated in SmBM+0.5\% FBS in the absence or presence of unoxidized LDL or moxLDL $(2 \mu \mathrm{g} / \mathrm{ml})$ for $3 \mathrm{~h}$ and $21 \mathrm{~h}$. The reactions were performed in quadruplicates. DNA-free mRNA was extracted from the cells and mRNA samples from corresponding cell cultures were pooled to reduce inter-sample variation. Biotinylated cRNA samples were hybridized to HG-U133A oligonucleotide Gene Chip arrays (Affymetrix, Santa Clara, CA). The data files from the arrays were analyzed using Affymetrix GeneChip ${ }^{\circledR}$ Operating Software (GCOS) version 1.0 (Affymetrix, Santa Clara, CA) to identify differentially expressed genes.

\section{Re-processing of gene expression data for Gene Set Enrichment Analysis}

The originally published set of differentially expressed genes only contained those surpassing a threshold (at least 2-fold differentially expressed), however GSEA requires input of all genes ranked from most overexpressed to most under-expressed. To gather this information, we reprocessed the original Affymetrix HGU133A CEL image data files using the Affy library of the Bioconductor package for the $\mathrm{R}$ programming language [35]. Three arrays exist in this experiment: control, treatment after $3 \mathrm{~h}$ and treatment after $21 \mathrm{~h}$. Background correction and normalization was performed on the datasets using the RMA method [36]. This data was then reformatted for input into the GSEA software (GCT file format).

\section{Gene Set Enrichment Analysis (GSEA) based pathway analysis}

Pathway enrichment analysis was carried out by searching for enriched gene-sets (e.g. pathways, molecular functional categories, complexes) in the early time point (3h) vs. control and the late time point (21h) vs. control using GSEA. It was not possible to use a statistical test to establish a gene ranking, as only gene expression data from one pooled set of samples was available for each experimental condition. Instead, a fold-change metric was used, computed by GSEA, comparing moxLDL-3h vs. Control and moxLDL-21h vs. Control. We used "gene set permutation" with 1000 permutations to compute $\mathrm{p}$-values for enriched gene-sets, followed by GSEA's standard multiple testing correction. We used GSEA's built- in gene identifier (ID) conversion system to convert Affymetrix probeset IDs from the expression data matrices to gene symbols for analysis. We used an updated version (September 2, 2011) of a custom gene set collection previously used for pathway analysis [37] (http://baderlab.org/GeneSets). The collection comprises Gene Ontology annotations [38], as well as pathways from the HumanCyc [39], Kyoto Encyclopedia of Genes and Genomes (KEGG) [40], MSigDB [33], NCI Nature Pathway Interaction Database (PID) [41], NetPath [42] and Reactome [43] databases.

\section{Enrichment Map pathway analysis visualization}

The resulting enrichment results were visualized with the Enrichment Map plugin for the Cytoscape network visualization and analysis software. We loaded GSEA results using a p-value cut-off of 0.005 and a q-value threshold of 0.1 . In these maps, each gene set is symbolized by a node in the network. Node size corresponds to the number of genes comprising the gene-set. The enrichment scores for the gene-set are represented by the node's color (red indicates up-regulation, blue represents down-regulation). The color of the node center indicates the enrichment score for the early time point (3h), and the node border color indicates the score for the late time point $(21 \mathrm{~h})$. To intuitively identify redundancies between gene sets, the nodes are connected with edges if their contents overlap by more than $50 \%$. The thickness of the edge corresponds to the size of the overlap. We used version 1.2 of the Enrichment Map software in Cytoscape 2.8.2.

\section{GeneMANIA}

GeneMANIA (http://www.genemania.org/) finds other genes that are related to a set of input genes, using a very large set of functional interaction data [44]. Interaction data include protein and genetic interactions, pathways, co-expression, co-localization and protein domain similarity. We searched the GeneMANIA web site using differentially expressed genes underlying specific functional themes to find out how the genes interact with each other. The resulting sub-network containing our query genes and additional related genes helps interpret the mechanistic details of the functional themes we define.

\section{Ingenuity pathway analysis}

We also used the commercial software Ingenuity Pathway analysis (Ingenuity ${ }^{\circledR}$ Systems; IPA) (http://www. ingenuity.com/) to identify enriched pathways and functional themes, as reported previously [45]. In particular, 
genes of interest, defined as those genes that were at least 2-fold differentially expressed, as reported in the original publication [32] were uploaded into the application as standard human gene symbols. Each gene identifier was mapped to its corresponding gene object in the Ingenuity Pathways Knowledge Base (IPKB). The IPKB, containing a large network of curated molecular interactions and pathways, was searched to find sub-networks enriched in genes of interest. A total of 77 and 205 genes were found to be network eligible for the $3 \mathrm{~h}$ and $21 \mathrm{~h}$ moxLDL experiments, respectively. Graphical representations of these sub-networks, containing direct and indirect molecular relationships, were generated.

\section{Results and discussion}

\section{Overview of the integrative pathway analysis}

Our GSEA-based analysis was summarized with the visualization of an enrichment map depicting a variety of molecular processes, here termed "functional themes" (Figure 1). These themes are listed in Additional file 1: Table S1, with a brief summary of their expression behavior at both $3 \mathrm{~h}$ and $21 \mathrm{~h}$ time points, following moxLDL treatment. We observed an up-regulation of genes in functional themes related to proliferation, cell migration, ECM production, cholesterol biosynthesis and protein translation (Figure 1). These observations are consistent with the hallmarks of SMC transformation. The differential gene expression patterns for specific functional themes of interest, mostly non-reported in the SMC transformation, are also shown as heat maps. For instance, it is evident that the "endopeptidase inhibition" theme is significantly down-regulated (Figure 1, Additional file 1: Table S1) and several members of the Serpin family of protease inhibitors are significantly down-regulated at $21 \mathrm{~h}$, as shown in the associated heat map (Figure 2). This down-regulation suggests increased proteolytic activity during SMC transformation. To our knowledge, endopeptidase activity has not been reported to play any role in SMC transformation. Other heatmaps of interest are shown in Additional file 2: Figure S1. In a complementary fashion, the investigation of canonical pathways at $3 \mathrm{~h}$ (Additional file 3: Table S2) and 21h (Additional file 4: Table S3) using IPA, revealed enrichment in specific signaling and metabolic pathways. The 20 most significant ones were selected for further study (Figures $3 \mathrm{~A}$ and $3 \mathrm{~B}$, respectively). Of note, JAK/STAT, Interleukin and IGF-1 signaling pathways, were deregulated at both time points. The dataset was further organized to predict how moxLDL treatment on SMCs might influence the cross-talk among interacting proteins. We identified eight major networks involving differentially expressed genes (4 networks at 3h; 4 networks at $21 \mathrm{~h}$ ). Interestingly, certain molecules in these networks (see below for details) were found to nucleate clusters of protein-protein interactions that may act as organizational "hubs" and additionally verified certain functional themes of the GSEA-based pathway analysis.

\section{In-depth pathway analysis of specific molecular themes of interest \\ Cholesterol biosynthesis}

Since the molecular mechanisms for SMC phenotype transformation during AT have not yet been clearly delineated, we initially examined the cholesterol biosynthesis theme (Figure 1) in SMC stimulated with moxLDL for $3 \mathrm{~h}$ and $21 \mathrm{~h}$ in detail (Figure 4A). Eight cholesterol synthesis-related genes were up-regulated in $3 \mathrm{~h}$ with LDLR, IDI1, HMGCS1, INSIG1 moderately up-regulated and HMGCR highly up-regulated. Seven genes were down-regulated with INSIG2 and APOE being the most strongly decreased ones (Figure 4B). A GeneMANIA network analysis for interactions among the gene products suggested an initiation of cholesterologenesis with HMG-CoA synthetase (HMGCS), conversion of acetylCoA and acetoacetyl-CoA to 3-hydroxy-3-methylglutaryl- CoA (HMG-CoA) and subsequent HMG-CoA reductase (HMGCR) catalysis of the rate-limiting step in cholesterol biosynthesis by converting HMG-CoA to mevalonate (Figure 4C). INSIG1 accelerates the degradation of HMGCR in the proteasome [46]. SCAP binds and retains INSIG1 in the ER and the binding of INSIG1 to SREBP1 and 2 facilitates SCAP-mediated transport of SCAP-SREBP complexes to the Golgi complex for degradation [47]. In the presence of sterols, INSIG2 regulates lipid synthesis by blocking the proteolytic activation of SREBPs by SCAP [48]. The down-regulation of SCAP, SREBF2 and INSIG2 and up-regulation of INSIG1, HMGCS1 and HMGCR in moxLDL-SMC indicates the initiation of cholesterol synthesis in the $3 \mathrm{~h}$ moxLDL-SMC cells.

Cholesterol metabolism genes in $21 \mathrm{~h}$ moxLDL-SMC were more robustly regulated with 26 genes up-regulated and 7 genes down-regulated. The most highly upregulated genes were G6PD, INSIG1, HMGCS1, FDPS and LSS and the most strongly down-regulated genes were APOE, LEPR, INSIG2, CYP51A1 and TNSF4 (Figure 4B). GeneMANIA network analysis indicated that genes encoding enzymes essential for the sequential enzymatic conversion of Acetyl-CoA and Acetoacetyl-CoA to cholesterol were all up-regulated in moxLDL-SMC (Figure 4C). The analysis also showed multiple interactions among the enzymes (including FDFT1, NSDHL, HSD17B7, LSS, SOLE, SC5DL, SC4MOL and CYP51A1) involved in the sequential conversion of farnesyl pyrophosphate to squalene, oxidosqualene, lanosterol and finally cholesterol and suggested that these enzymes are hub proteins or function as a multi-subunit complex. 


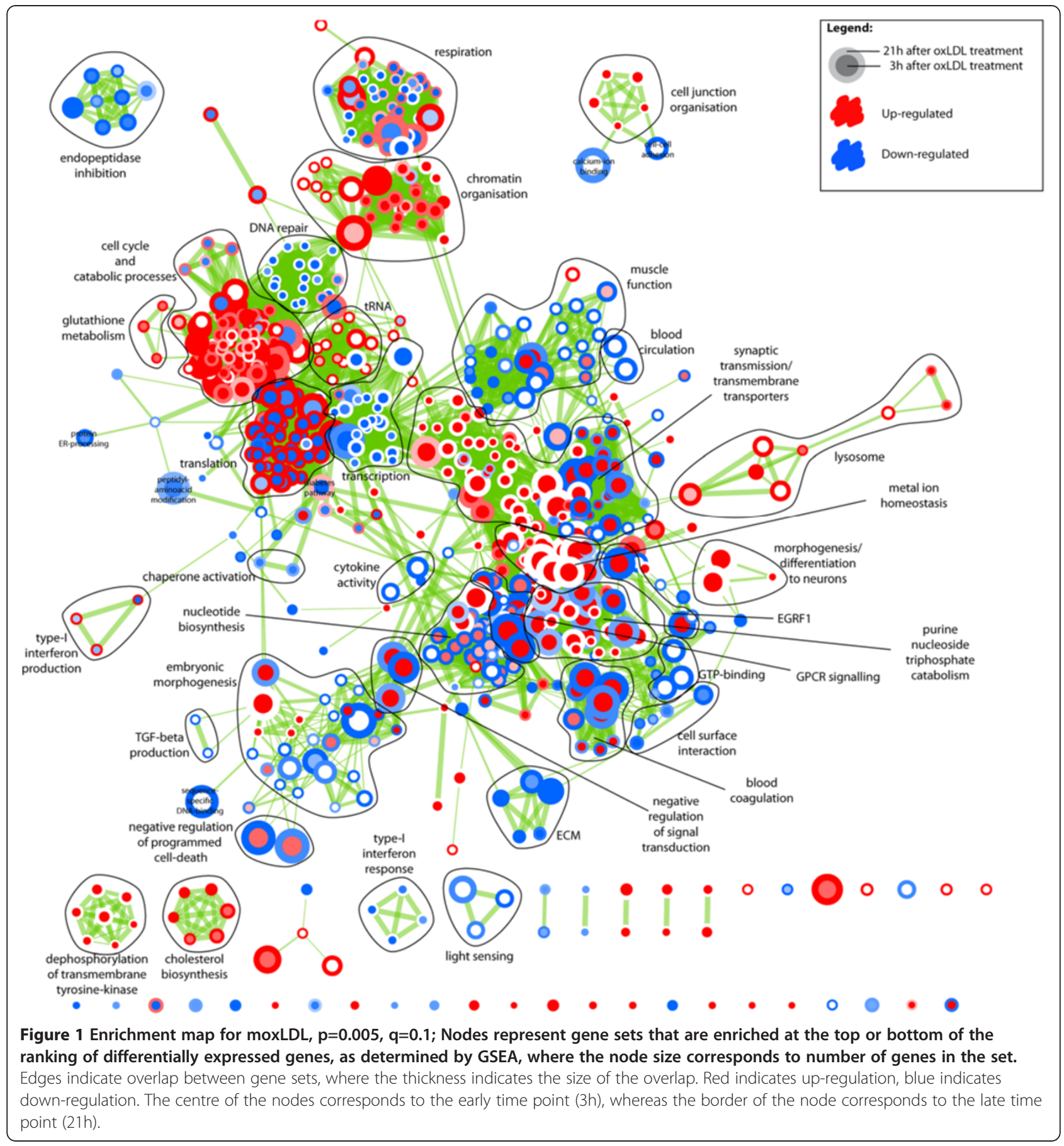

The ER-bound INSIG-SCAP-SREBP complex is the most important sensor of sterol levels. At high cholesterol levels, the complex is retained in the ER, but at lower levels the SCAP-SREBP enters transport vesicles [47]. In the Golgi, SREBP undergoes two steps of proteolysis, releasing a soluble transcription factor that regulates many genes associated with cholesterol and lipid metabolism. This leads to increased synthesis of cholesterol and LDL receptors. A switch-like response that helps to maintain cellular cholesterol in a narrow range has been demonstrated in the ER. It is currently unclear whether the sharp transition is due to cooperative protein-protein interactions between SCAP molecules or an abrupt change in the chemical activity of cholesterol in the ER membrane when it crosses a threshold value [49]. It has been proposed that the level of expression of INSIG1 protein can influence the cholesterol-dependent transition point, and reduction of cholesterol levels leads 


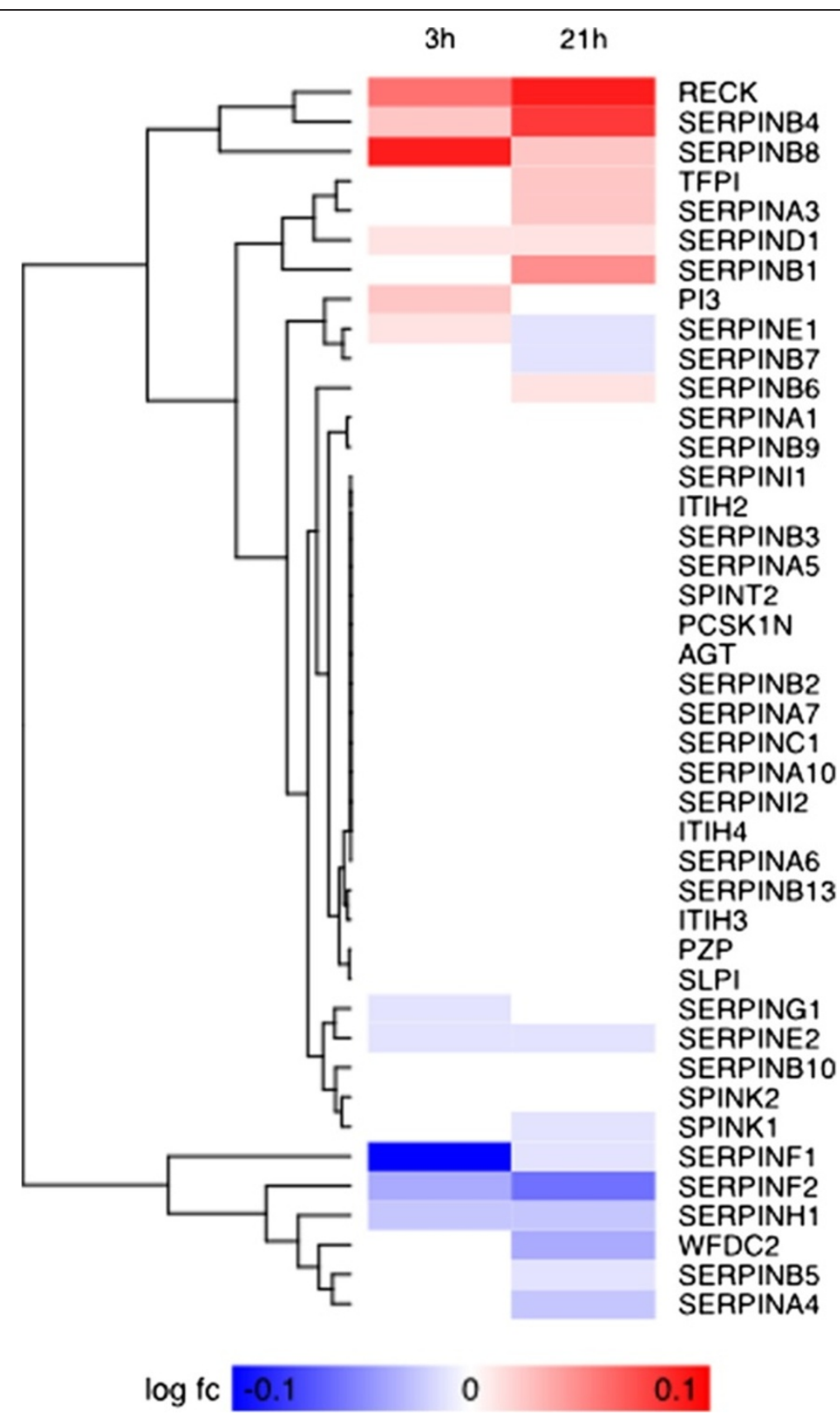

Figure 2 'Endopeptidase Inhibition' theme heatmap of representative SMC differential gene expression patterns induced by treatment with moxLDL at $3 \mathrm{~h}$ and $21 \mathrm{~h}$.

to proteasomal degradation of INSIG1, which sensitizes cells to cholesterol depletion [46]. In our study, INSIG-1 is highly expressed at $21 \mathrm{~h}$ and thus we predict sustained cholesterol synthesis would occur.

PDGF has been shown to regulate ABCA1 expression in SMC [50]. However in our study, both ABCA1 and ABCG1 were not expressed in moxLDL-treated SMC at $3 \mathrm{~h}$ and $21 \mathrm{~h}$, in spite of an increased PDGF expression and cholesterol biosynthesis. We propose that the lack of ABCA1 and ABCG1 in moxLDL-treated SMC, would result in impaired cholesterol efflux leading to its accumulation in SMCs during atherogenesis. This finding is thus analogous to the observed down-regulation of ABCA1 and ABCG1 transporters in lipid laden macrophages which results in a dysregulated reverse cholesterol transport pathway that enhances lipid accumulation and "foam cell" formation in moxLDL-treated macrophages [51-55]. 


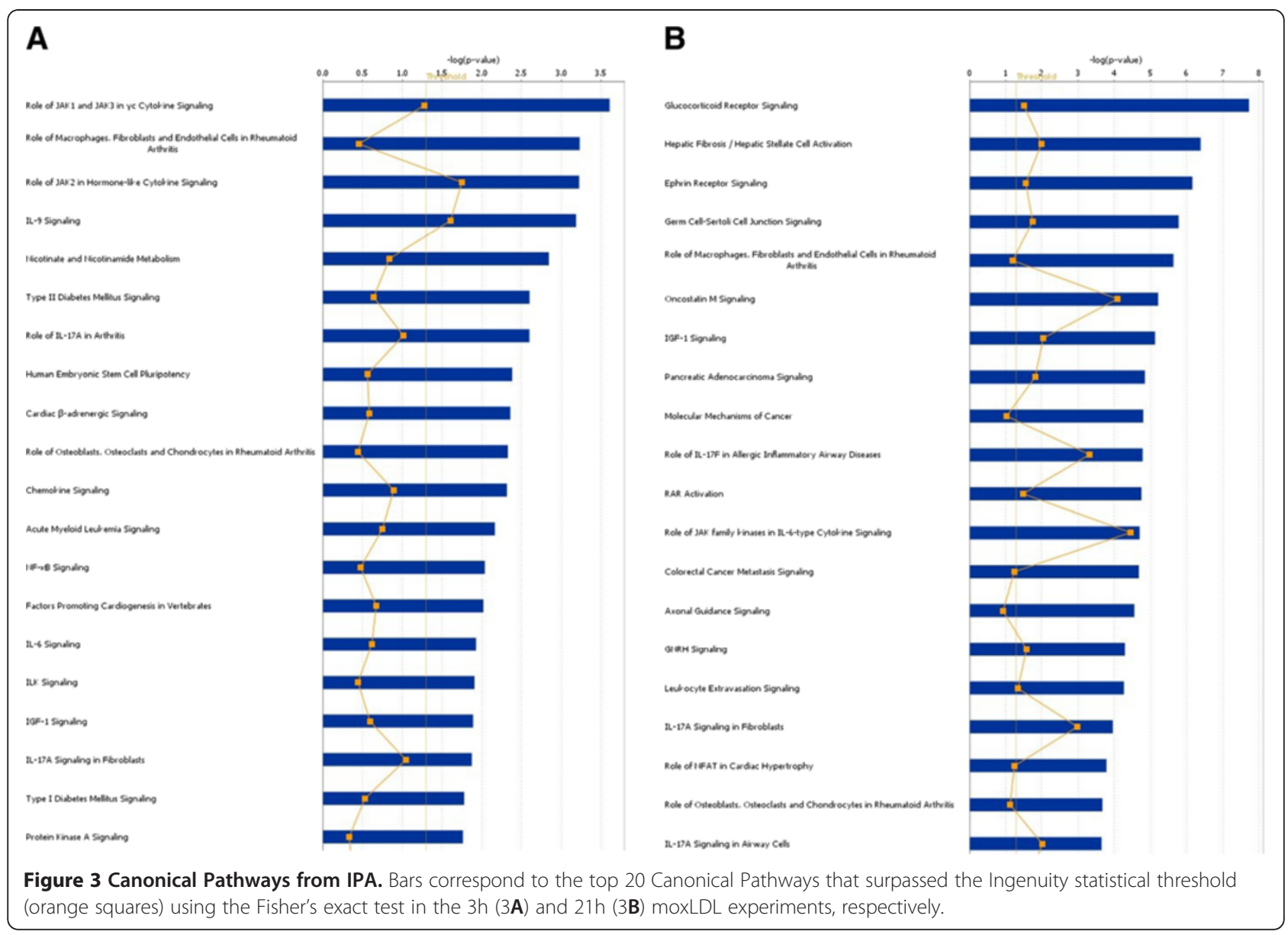

The ER contains acetoacetyl CoA thiolase (ACAT1), the enzyme responsible for esterifying excess cholesterol for storage in lipid droplets [56]. Cholesterol ester storage and accumulation as oil droplets in microsomes occurs during cholesterologenesis and may contribute to formation of fatty streaks. NAD(P)H dehydrogenase-like protein (NSDHL), a C4 demethylase that is involved in the removal of $\mathrm{C}-4$ methyl groups from the cholesterol precursor lanosterol, is localized to the surface of the ER. It also accumulates on the surface of lipid droplets that function as intracellular storage compartments for neutral lipids and cholesterol esters and participates in the regulation of cellular cholesterol content [57]. The up-regulation of NSDHL in moxLDL-SMC may therefore play a role in the accumulation of cholesterol in moxLDL-SMC.

Cholesterol metabolism was tightly regulated in $21 \mathrm{~h}$ moxLDL-SMC, judging by the differential regulation of the network of LDLR, LDLRAP1, LIPA, RXRA, APOC3 and APOL2 genes (Figure 4C). LDLRAP1 is required for internalization of the LDL-LDLR complex in endocytic vesicles [58]. Lysosomal acid lipase (LIPA) has been reported to play an important role in cellular metabolism by releasing cholesterol, which in turn suppresses further cholesterol synthesis and stimulates esterification of cholesterol within the cell. ApoE knock-out mice spontaneously develop atherosclerosis. However, this effect is counteracted by the retinoid X receptor (RXRA) in the same model [59]. APOC3 inhibits the catabolism and hepatic uptake of apoB-containing lipoproteins and enhances the catabolism of HDL particles, as well as the adhesion of monocytes to vascular endothelial cells and activates inflammatory signaling pathways [60]. The upregulation of APOC3 in moxLDL-SMC would inhibit cholesterol clearance via HDL. Interestingly, the observations of up-regulation of LDLR, LDLRAP1, INSIG1, SCAP, LIPA, RXRA, NSDHL, APOC3 and APOL2 and the down-regulation of INSIG2 and APOE in moxLDLSMC further suggest a dysregulation of cholesterol metabolism and clearance in moxLDL-SMC, a situation that favors foam cell formation. APOL2 has not been reported to be expressed in neointima or the media but is up-regulated in HUVECs following prolonged stimulation with TNF- $\alpha$ [61-63].

To date, statins are used therapeutically to inhibit de novo hepatic cholesterol synthesis to lower the levels of plasma LDL-cholesterol, the major risk factor for atherosclerosis and coronary heart disease. Inhibition of 

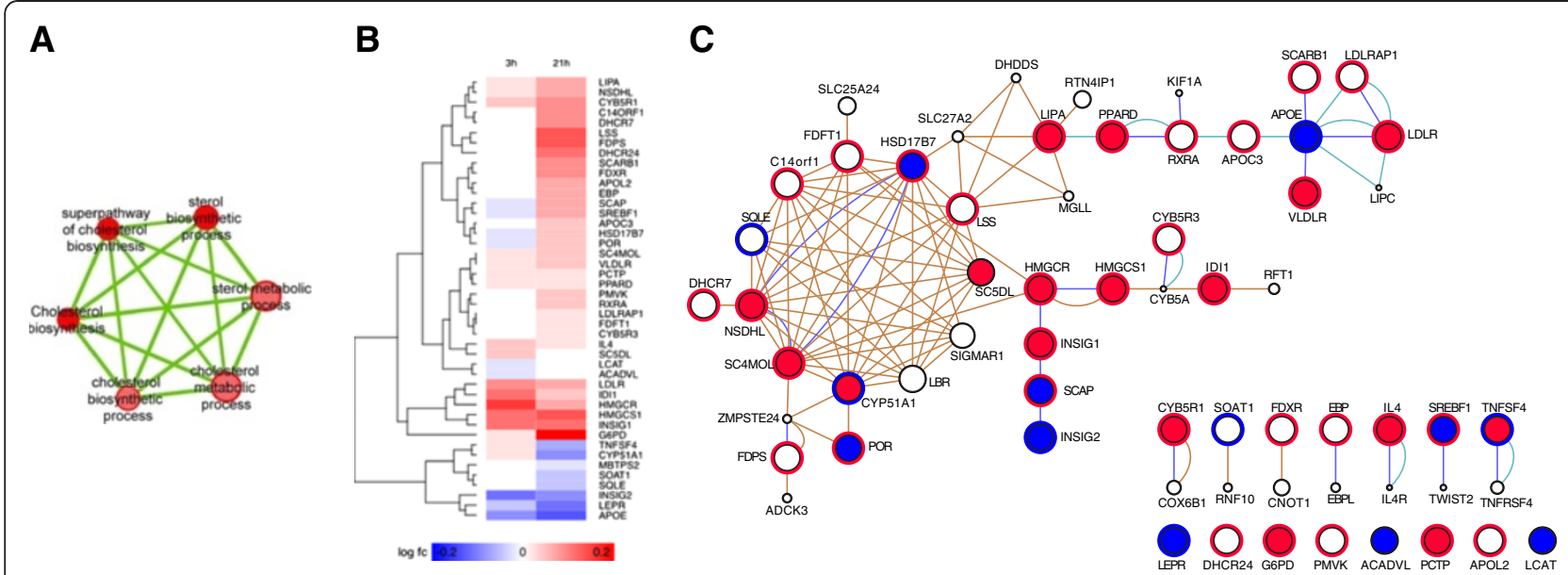

Figure 4 Cholesterol biosynthesis theme analysis. (A) Cholesterol biosynthesis theme from enrichment map. (B) Cholesterol biosynthesisassociated heatmap. (C) Network of interactions among moxLDL-SMC cholesterol metabolism related genes, as retrieved by the GeneMANIA website, colored by gene expression at $3 \mathrm{~h}$ (node center) and 21h (node border). Red indicates up-regulation, blue indicates down-regulation and white indicates no differential expression or no expression data available. Circles represent genes and connecting lines represent interactions between genes. The network was generated using a GeneMANIA query of 43 cholesterol synthesis related genes (large circles) differentially expressed at either $3 \mathrm{~h}$ or $21 \mathrm{~h}$. GeneMANIA retrieved known and predicted interactions between these genes and added extra genes (smaller white circles) that are strongly connected to query genes (we used the default setting of 20 additional connecting genes). Light blue lines indicate pathway interactions from the Reactome pathway database, dark blue lines indicate experimentally determine physical interactions, from various protein interaction databases included in GeneMANIA, and brown lines indicate predicted interactions, mostly from the I2D database of protein interactions predicted from experimentally determined physical interactions in other species. GeneMANIA advanced settings were used to search only physical, pathway and the default set of predicted networks. We excluded co-expression, co-localization and genetic interaction networks from the search to focus the analysis on higher confidence physical and pathway interactions.

HMGCR conversion of HMG CoA to mevalonic acid results in an inhibition of the synthesis of several nonsterols such as dolichols and ubiquinone and contributes to the side effects observed in patients on statin therapy. Consequently, attention has been directed towards enzymes such as squalene synthetase, squalene epoxidase and oxidosqualene cyclase, which are involved in cholesterol synthesis beyond farnesyl pyrophosphate as potential targets. Preclinical studies with oral bioavailable inhibitors have demonstrated the potential of squalene epoxidase inhibitors as hypocholesterolemic agents, however high circulating levels of squalene epoxidase inhibitors are believed to be responsible for dermatitis and neuropathy observed in the participants [64]. To the best of our knowledge, the hypocholesterolemic effects of inhibitors of the enzymes involved in post-squalene cholesterol biosynthesis have not yet been reported. These enzymes [including LSS, SC5DL, CYP51A1, SC4MOL, NSDHL, HSD17B7 and C14orf1 (Figure 4C)] exhibit extensive physical interactions with each other, suggesting they may form a scaffold and act via a multistep multi-enzyme process. Inhibition of any one of the enzymes may destabilize the complex and inhibit cholesterol formation. They, thus, could be considered potential targets for the design of hypocholesterolemic drugs for therapeutic intervention of SMC phenotype transformation and atherogenesis.
The significance of moxLDL-mediated induction of cholesterol synthesis in SMC phenotype transformation is believed to be related to the proinflammatory properties of atherogenic LDL particles. According to the "oxidation hypothesis of atherogenesis", specific proinflammatory oxidized phospholipids that result from the oxidation of LDL phospholipids containing arachidonic acid are largely generated by potent oxidants produced by the lipoxygenase and myeloperoxidase pathways. These so-called mildly or minimally oxidized LDL and their active components, such as polyoxygenated cholesteryl ester hydroperoxides, are recognized by the innate immune system via Toll-like receptor (TLR) activation (such as TLR4). This leads to the recruitment of spleen tyrosine kinase (Syk), cytoskeletal rearrangements and macropinocytosis which in hyperlipidemic environments leads to excessive lipid accumulation in monocytes, macrophages and SMC in vascular lesions, foam cell formation, vascular inflammation and ultimately the development of atherosclerotic plaques [65,66]. TLR engagement stimulates multiple signaling pathways, including PI3-K/ Akt and p38/p42/p44 MAPKs, which activate transcription factors (e.g. NFkB, IRFs, STAT1, STAT3, AP-1). The activation of these pathways also activates the expression of proinflammatory cytokines (e.g. IL1 $\alpha$ TGF $\beta$, MCP-1, IFN $\gamma$ ) and growth factors (e.g. PDGF, IGF, EGF, FGF) involved in mitogenesis of VSMCs 
[67-76]. The various functional themes and pathways that we have analyzed substantiate these observations and suggest further details about the molecular mechanisms of SMC phenotype transformation.

\section{Inflammatory cytokines and growth factors}

GSEA-based and IPA analysis found large clusters of cytokines, including IL-1, IL-12, CSF-3, TGF- $\beta$, PDGF and HGF, grouping many of the differentially expressed genes of the dataset (Figure 1, Figure 5A). Other networks identified "hubs" belonging mainly to the IFN- $\alpha$, PDGF, NF-kB, VEGF and JAK/STAT signaling pathways (Figure 5B). Such networks were also found in the $21 \mathrm{~h}$ treatment experiments, where members of the interleukin family of proteins nucleated clusters of signaling molecules regulating cell growth, proliferation and migration (Figure $5 \mathrm{C}$ ). Cytokines and growth factors, including Interleukins (IL-6, IL-1 $\beta$ ), TGF- $\beta$, PDGF, HGF, IGF-1 and members of the IFN family, have been shown to activate signal transduction cascades that trigger remodeling of the cytoskeleton and change cell-to-matrix adhesion [77]. Hepatocyte growth factor (HGF), previously linked to the regulation of cell motility and migration especially in cancer and atherosclerosis [78], nucleated a network with members of the MAPK family. In another network, IFN- $\gamma$ was the major molecular "hub" (Figure 5D). IFN- $\gamma$, known to be released at sites of inflammation and in large amounts in the plaque, induces vasodilation and synthesis of $\mathrm{NO}$ by SMCs, which in turn contributes to hyperemia of inflammation. IFN- $\gamma$-induced $\mathrm{NO}$ synthesis by SMCs may also be involved in the regulation of vascular tone and proliferation of SMCs $[79,80]$. To the best of our knowledge, the activation of IL12, IFN- $\alpha$, HGF and VEGF signaling pathways in SMC undergoing phenotype transformation has not been reported. In a complementary fashion, canonical pathways belonging to these networks were also enriched in our dataset, as seen in Figures 3A and 3B.

MicroRNAs (miRNAs) have recently been implicated in the regulation of atherosclerosis and lipoprotein metabolism, by affecting endothelial integrity, macrophage inflammatory response to atherogenic lipids, vascular smooth muscle cell proliferation, and cholesterol synthesis [81]. We found that certain miRNAs (miR-203, miR-511, miR590-3p, miR-346*/miR-1207-5p/miR-4763-3p) serve as organizational hubs of several signal transduction pathways in one of our IPA networks (Figure 5D). Since miRNAs are implicated in inflammatory processes that accompany heart failure, AT, coronary artery disease, obesity and diabetes [82], we further investigated these pathways. Many of the identified miRNAs, along with clusters of deregulated proteins were, indeed, highly connected to the IFN- $\gamma$ pathway in the same molecular network (Figure 5D). Interestingly the JAK/STAT, MAPK and IGF signaling pathways, which have been shown to play clearly defined roles in AT pathogenesis [83-85], served as major intracellular mediators of the cytokine pathways in the generated molecular networks. Recent integrative approaches demonstrating a plethora of IFN- $\gamma$-regulated mRNAs and targeted mRNAs [86], coupled with our observation of miRNAs in the IFN$\gamma$-dominated molecular network suggest that inflammatory signaling may be regulated through non-classical miRNArelated cytokine pathways, beyond the classical JAK/STAT and MAPK pathways.

\section{G-protein coupled receptors (GPCRs)}

VSMC migration involves a dominant plasma membrane leading lamellae, or leading edge, protruding from the cell to make contact with an extracellular substrate. Binding is accomplished via integrin transmembrane receptors that enable the formation of focal complexes and secure focal adhesions. An intracellular signal transduction cascade, involving G-protein and tyrosinekinases, results in the alignment of actin filaments and a myosin contraction within the leading edge. Focal adhesions are subsequently disengaged over the remainder of the cell surface, and contractile forces propel the cell forward in the direction of the anchoring leading edge [87-91]. Thus, VSMC migration is predominantly regulated by two receptor-coupled systems, GTP-binding protein (G-protein)-coupled and tyrosine kinase-coupled proteins. Signal transduction pathways from these two systems appear to intersect as signals are transmitted.

To-date the mechanism of action of GPCRs in SMC migration has not been well delineated. The differential expression of the member genes of the GPCR theme (Figure 1, Figure 6A) is shown in the associated heat map (Figure 6B). Many of these genes (e.g. GPR1, GPR64, GPRC5A, and GPR171), expected to be involved in regulating SMC transformation, are up-regulated, whereas Frizzled6, Frizzled8, GPR176, GPR32, GPR25, and GPR124 are down- regulated. Frizzled2 is down-regulated at $3 \mathrm{~h}$ but strongly up-regulated at $21 \mathrm{~h}$. The receptors encoded by these genes are specific to different signaling molecules. The fact that one group of receptors seems to be produced increasingly at the expense of a second group could indicate a shift of the cell's responsiveness to different sets of signals. The most strongly up- and downregulated genes in the GPCR functional theme encode various chemokines (CCL19, CCL20, CXCL2, and CXCL12). These observations suggest that GPCRs could regulate cell migration and trafficking of immune cells as well as VSMC early in the course of mox-LDL treatment $(\sim 3 \mathrm{~h})$ and that their effects might not be retained at later events ( 21h) (Figure 1, Figure 6B, Table 1). Additionally, an IPA network of particular interest for the $3 \mathrm{~h}$ treatment experiment is shown in Figure 6C, where GPCRs interact indirectly with members of the MAPK signaling pathway, 


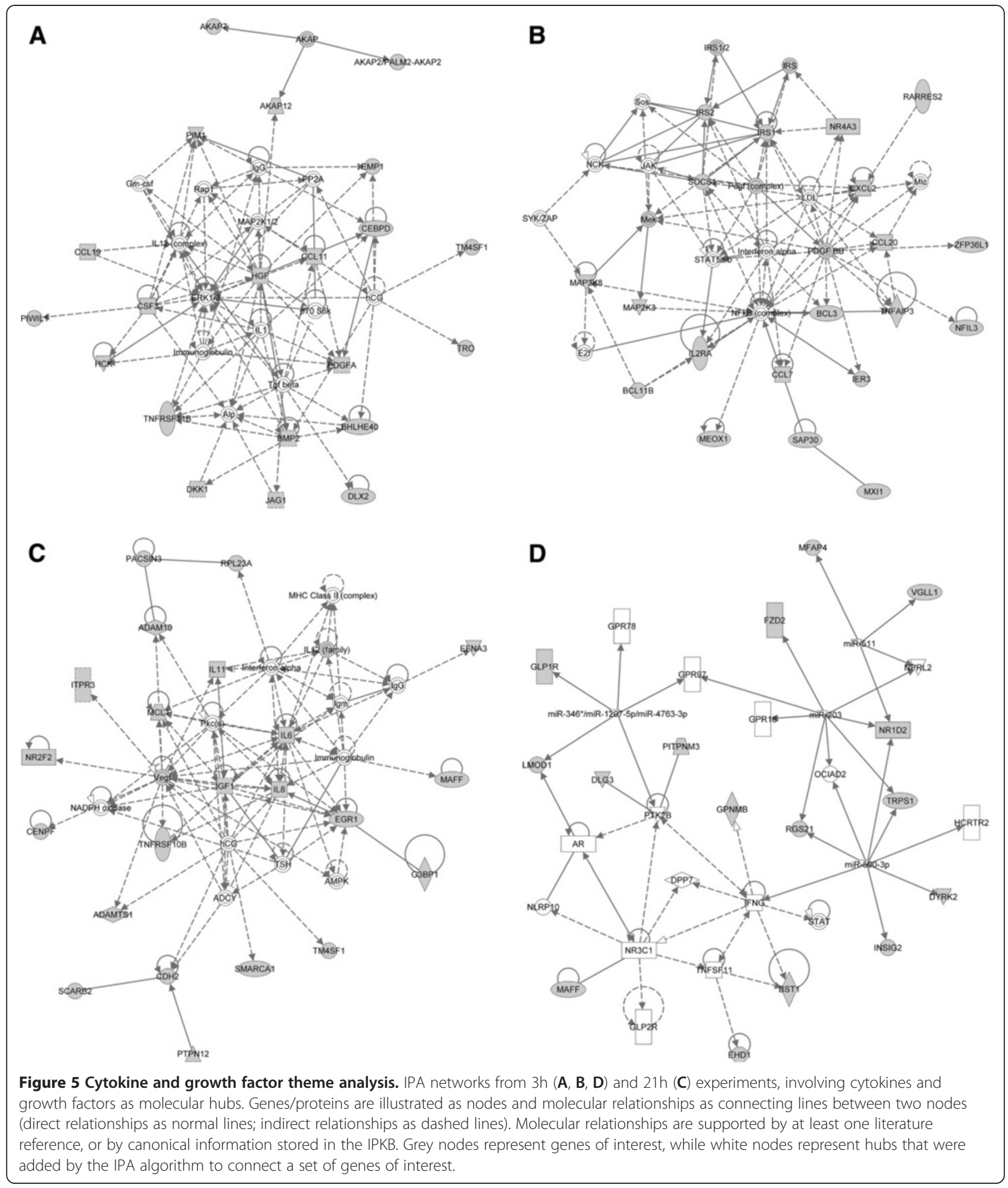

and thus may be regulating important biological processes, such as cell growth and proliferation, migration and differentiation. Moreover, the GPCR family also acts as an organizational hub in the $21 \mathrm{~h}$ experiment (Figure 6D), during which the enrichment map shows a significant down-regulation of the GPCR functional theme (Figure 6A), as already described. IPA proposed that GPCRs regulate important signaling pathways, several of which are revealed in our molecular networks (Figure 6D): For example, (a) Rac, is a member of the Rho family of 


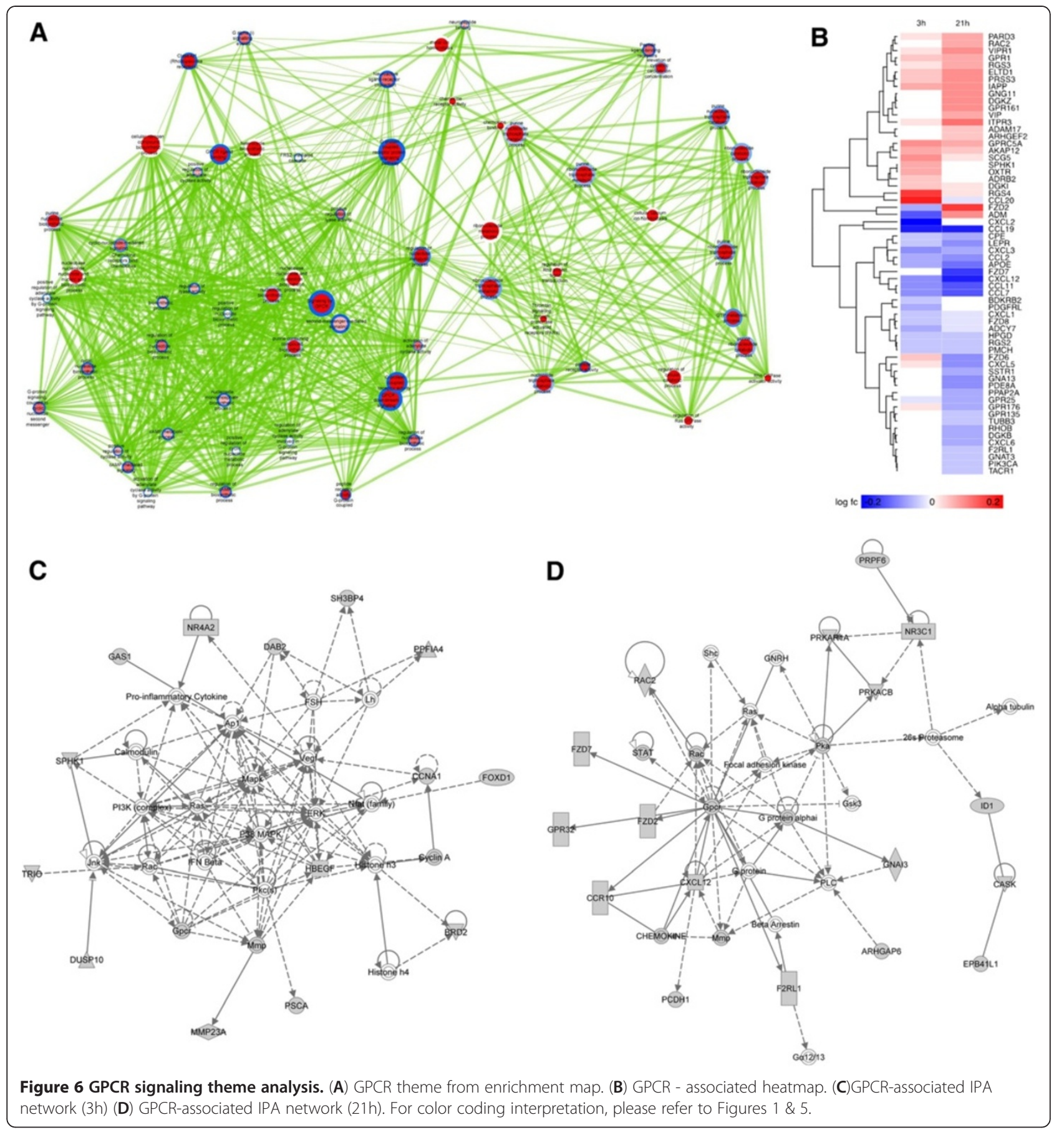

proteins. Rho kinases have been widely demonstrated to be up-regulated in activated SMCs by inflammatory stimuli [90], (b) CXC-motif type chemokines, which regulate chemotactic responses, may participate in the recruitment of inflammatory cells to sites of atherosclerosis development [92], (c) FAK, focal adhesion kinase, which is involved in integrin-dependent cell-to-matrix adhesion signaling, is important for migration in the extracellular matrix [93], (d) members of the JAK/STAT pathway, such as STAT5, are involved in SMCs activation in atherosclerosis [84] and (e) MMPs which are major extracellular proteolysis enzymatic systems that modify ECM, have evident roles during inflammatory and vascular diseases [94].

Our enrichment map provides information regarding the activity status (up- or down-regulation) of GPCR signaling pathways during SMC transformation, while Ingenuity identifies cross-talk of this pathway with other pathways. Based on these observations, we speculate that 
Table 1 Novel Findings of the Integrative Pathway Analysis of moxLDL-induced SMC Phenotype Transformation

\begin{tabular}{|c|c|}
\hline Theme & Novel Findings \\
\hline Cholesterol synthesis \& transport & $\begin{array}{l}\text { The observation of upregulated cholesterol biosynthesis coupled with a dysregulation of the reverse cholesterol } \\
\text { transport pathway in moxLDL-induced SMC may promote the accumulation of cholesterol and cholesterol } \\
\text { esters in the cells, and facilitate foam cell formation during atherogenesis }\end{array}$ \\
\hline GPCR signaling & $\begin{array}{l}\text { Observed GPCR signaling may have a role in SMC transformation. GPCR signaling following activation via inflammatory } \\
\text { or other microenvironmental stimuli have been implicated in responses, such as change of cell-to-cell and cell-to-matrix } \\
\text { adhesion, matrix remodeling, cell proliferation, migration, and immune cell trafficking and regulation. The activation of } \\
\text { GPCR pathways may thus play a role in the initiation of SMC dedifferentiation and phenotype transformation. }\end{array}$ \\
\hline Cytokine \& growth factor & Potential role for IL12, IFN-a, HGF, CSF3 and VEGF signaling in SMC phenotype transformation. \\
\hline Cell cycle control & $\begin{array}{l}\text { Up-regulation of HBP1, a repressor of cyclin D1 and CDKN1B, suggests a negative feedback loop auto-triggered } \\
\text { by the up-regulation of the core cell cycle machinery during SMC phenotype transformation. }\end{array}$ \\
\hline Cell differentiation & $\begin{array}{l}\text { The deregulation of the ID2 and ZEB1 regulators of differentiation during SMC phenotype transformation is } \\
\text { consistent with the onset of SMC de-differentiation. }\end{array}$ \\
\hline miRNA \& de-differentiation & Potential role of miRNAs in the regulation of SMC phenotype transformation via interactions with the IFN- $\gamma$ pathway. \\
\hline Nexus genes in complex networks & $\begin{array}{l}\text { Several "nexus" genes, including the components of a multi-subunit complex involved in the terminal stages of } \\
\text { cholesterol synthesis, miRNAs (e.g. miR-203, miR-511, miR-590-3p, miR- 346*/miR-1207-5p/miR-4763-3p), members of } \\
\text { the GPCR family of proteins (e.g. GPR1, GPR64, GPRC5A,GPR171, GPR176, GPR32, GPR25, and GPR124) and signal } \\
\text { transduction pathways were observed. These genes may play important roles in VSMC phenotype transformation } \\
\text { and in the pathogenesis of AT and coronary artery disease and may provide novel targets for drug discovery. }\end{array}$ \\
\hline
\end{tabular}

The original microarray data analyzed here has been deposited in the Gene Expression Omnibus database (accession GSE36487), and is publicly available for the first time with this paper.

GPCR signaling plays a role in SMC transformation. GPCR signaling may mediate the initiation of SMC dedifferentiation following activation via inflammatory or other microenvironmental stimuli. The activation of GPCR pathways might be implicated in a large number of responses, such as change of cell-to-cell/cell-to-matrix adhesion, proliferation, matrix remodeling, migration, and immune cell trafficking and regulation. These traits are consistent with the SMC transformation process. Once these processes have been completed, GPCR signaling is down-regulated, by a mechanism that is yet to be elucidated. The maintenance of the activated SMC phenotype could be regulated by other "maintenance pathways", such as cytokine signaling pathways, which are up-regulated throughout the course of the disease. We believe that such maintenance pathways exist, given previous literature [22] and new evidence from our study that the migratory and proliferative phenotype in SMCs is maintained throughout moxLDL treatment by the strongly up-regulated cell cycle control machinery.

Members of the GPCR superfamily are known to mediate G-protein-coupled, cAMP-mediated signal transduction mechanisms for the detection of chemostimuli in the main olfactory epithelium and heterogeneous cells in mammals $[95,96]$. Since the olfactory sensing pathway was highly regulated in SMC exposed to moxLDL (Additional file 2: Figure S1), we speculate that in addition to moxLDL receptors, the GPCRs up-regulated in this process may participate in sensing this atherogenic agent.

\section{Cell adhesion}

SMC migration and proliferation induced by moxLDL contributes to the thickening of the intima in restenosis and AT. This process may be regulated by cadherins.
Cadherins are transmembrane proteins which form cellcell contacts. Studies by Uglow et al. (2003) [97] and Dwivedi et al. (2009) [98] have shown that MMP9 and -12-dependent shedding of the extracellular portion of $\mathrm{N}$-cadherin results in the disruption of $\mathrm{N}$-cadherin cellcell contacts. This process was shown to be associated with the release and translocation of beta-catenin to the nucleus and the induction of beta-catenin-mediated intracellular signaling. This signaling cascade results in the expression of cyclin D1 and increased VSMC proliferation mediated by PDGF-BB $[99,100]$. These observations prompted us to analyze the cell-cell junction theme (Figure 7A). Significant alterations of the cell adhesion programming are implied via multiple ways in our analysis: (A) A cadherin expressional switch accompanies the SMC phenotypic transition; CDH10, CDH5 are up-regulated, while $\mathrm{CDH} 19$ and $\mathrm{PCDH} 9$ are downregulated $21 \mathrm{~h}$ post-moxLDL treatment (Figure 7B). Cadherins belong to the adherens junction apparatus, mediating cell-to-cell, homotypic cell adhesion coupling in epithelial or even stromal cells [101]. It has been postulated that molecular "switching" in these molecules contributes to the turnover of cell adhesion properties of the cells in various pathologies and participate in motile phenotypes, as in the case of cancer metastasis or even normal development [102-104]. (B) Cluster of differentiation (CD) molecule expressional switching, accompanies SMC transition; CD151 and CD9 are up-regulated, whereas CD47 is down-regulated with moxLDL treatment (Figure 7B). CD9 is a cell-surface glycoprotein belonging to the tetraspanin family of proteins, believed to be involved in complexes with integrins, thus mediating cell migration, adhesion and platelet aggregation 


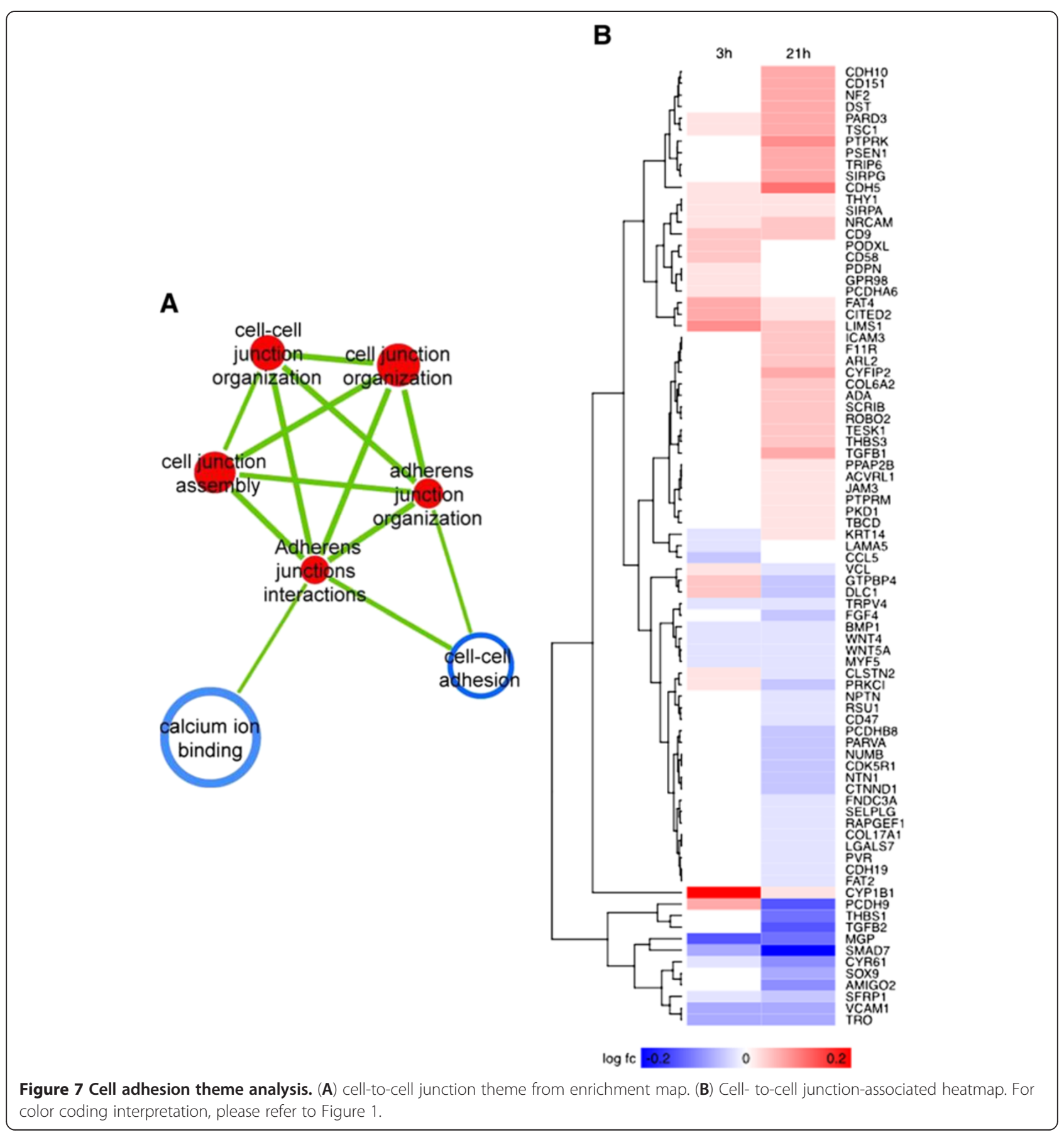

[105]. CD151, belongs to the same family of proteins, additionally shown to accelerate cancer metastasis, thus promoting a migratory phenotype [106]. (C) Overexpression of PARD3 (Figure 7B), a member of the Par3/Par6 polarity complex, might suggest that SMC transition is accompanied by a polarized migration [107]. Taken together, these observations point to altered cell-adhesion machinery in the activated SMC that is consistent with a migratory phenotype.

\section{Cell cycle control}

The cell-cycle theme (Figure 8A) served as a proof-ofconcept in our analysis, since cell cycle control and cell death machineries induce tremendous impact in tissue homeostasis of the adult organism, with known roles in inflammatory, vascular, neoplastic and neurodegenerative diseases [108]. Since the activated SMC phenotype is highly proliferative [4], disturbances in the cell-cycle control machinery are expected. The theme was clearly 


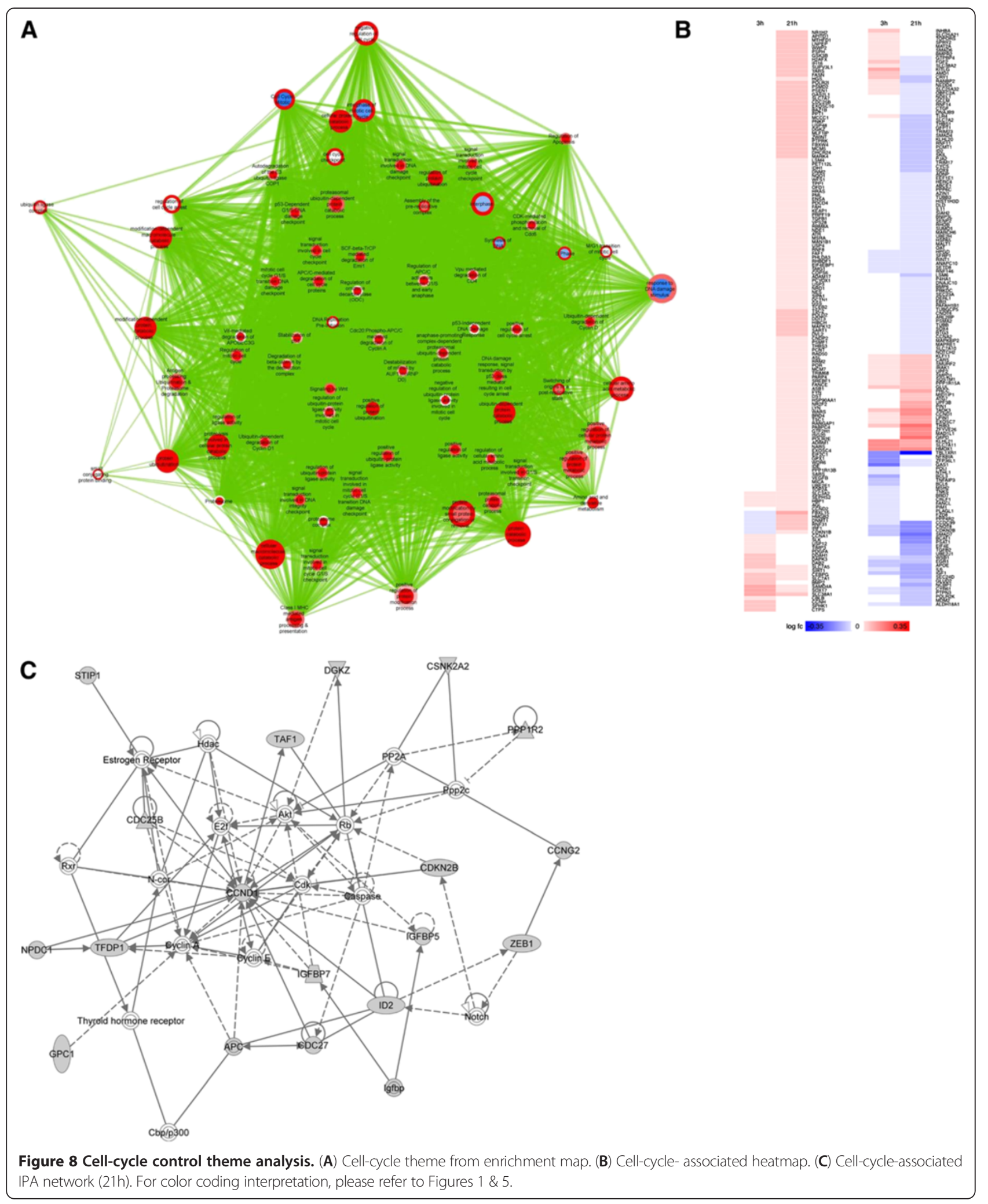


up-regulated in both time-points (Figure 8A, Table 1). Details drawn from the associated heatmap (Figure 8B) suggest that cyclin D1 is up-regulated and the cyclindependent kinase (CDKN) inhibitor, CDKN2B, is downregulated, which is consistent with $\mathrm{G1} / \mathrm{S}$ progression. Interestingly, HBP1 which is known to repress cyclin D1 [109], as well as CDKN1B are up-regulated, suggesting that a negative feedback loop to down-regulate cell growth could be already initiated, most probably triggered from the up-regulation of the core machinery. IPA also verified the involvement of the cell cycle control machinery in the $21 \mathrm{~h}$ time point (Figure $8 \mathrm{C}$ ). Specifically, proteins in our dataset are clustered around the key regulatory molecules of the cell cycle, such as the cyclin, the CDK, and the Rb/E2F family members (Figure $8 \mathrm{C}$ ).

\section{Cell differentiation}

An important aspect of SMC transition into a migratory and proliferative phenotype is the loss of the differentiated and quiescent phenotype. Regulatory factors of cell differentiation most likely regulate this transition. In one of our IPA networks (Figure 8C), we captured two potential regulators of differentiation: (a) DNA-binding protein inhibitor-2 (ID2), a transcriptional regulator which inhibits the function of basic helix-loop-helix transcription factors [110], and (b) Zinc-finger E-Boxbinding homeobox 1 (ZEB1), a transcription factor involved in the generation of more mesenchymal phenotypes [29]. Interestingly, both ID2 and ZEB1 were deregulated in our dataset. Although IL-1 $\beta$-induced ID2 gene expression has been described in SMCs [111], ZEB1 has not been reported to be involved in SMC phenotype transformation.

\section{Myogenic contraction mechanism}

It has been reported that moxLDL induces a sustained and intense calcium-dependent retraction of SMC by down-regulation of the expression of genes responsible for the synthesis of SMC contractile proteins such as $\alpha$ actin, smooth muscle myosin heavy chain-1, non-muscle myosin and calponin, a thin filament protein involved in the regulation of actin-myosin interactions [112]. moxLDL also stimulates collagen production, DNA synthesis and SMC proliferation [112,113]. A subnetwork of actin and actin-related gene/proteins was found in the $21 \mathrm{~h}$ experiment (Figure 9). This network clusters molecules, such as myosin, tropomyosin and cofilin around actin filaments, involved in the myogenic contraction mechanism. Interestingly, the enrichment map reveals a large down-regulation of the theme "muscle function" in the $21 \mathrm{~h}$ experiment (Figure 1). These observations are in concordance with cytoskeletal rearrangements, relevant to transformation of SMCs into the migratory phenotype [19].

** The novel findings in this paper are summarized in Table I.

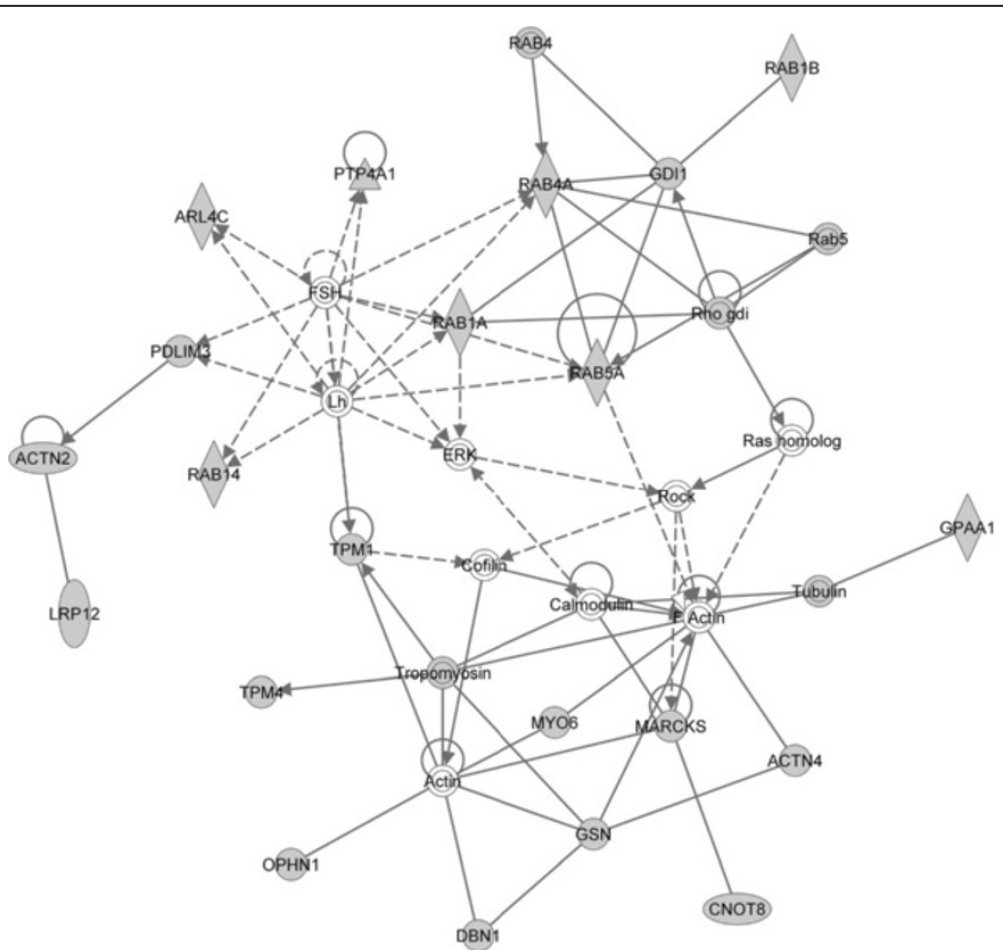

Figure 9 Myogenic contraction-associated IPA network. For color coding interpretation, please refer to Figure 5. 


\section{Conclusion}

Pathway analysis of the transcriptomic data of the in vitro model of moxLDL induced-VSMC phenotype transformation using GSEA, Enrichment Map Cytoscape plugin, GeneMANIA and IPA software identified several pathways known or expected to be disturbed during SMC transformation in addition to several novel regulators that may play key roles in the onset and progression of AT. The identification of these novel potential regulatory genes now permit hypothesis generation and in vivo functional experimentation (such as gain and loss-offunction studies) to establish causality with the process of SMC phenotype transformation, AT and coronary artery disease and to possibly reveal novel diagnostic markers and targets for drug discovery.

\section{Additional files}

Additional file 1: Table S1. List of functional themes (Column A), taken from the enrichment map (Figure 1), with their explained behavior, according to the node colors, at 3h (column B) and 21h (Column C) time points.

Additional file 2: Figure S1. Heat maps of SMC differential gene expression patterns, induced by treatment with moxLDL at $3 \mathrm{~h}$ and $21 \mathrm{~h}$. Partial information from these heat maps was used to draw Figures 4,6 , 7 and 8

Additional file 3: Table S2. IPA results. All the top-listed canonical (metabolic \& signaling) pathways using the Fisher's exact test in the $3 \mathrm{~h}$ (Additional file 1: Table S1) and 21h (Additional file 2: Table S2) moxLDL experiment, respectively. Column A depicts canonical pathway name as tagged in the Ingenuity knowledgebase; column B depicts the Fisher exact test $-\log (\mathrm{P}-$ Value); column $\mathrm{C}$ depicts the statistical threshold; column D provides the correspondence of the moxLDL differentially expressed genes to each of the individual canonical pathways. Partial information from these tables was plotted as Figures $3 \mathrm{~A}$ and $3 \mathrm{~B}$ in this manuscript.

Additional file 4: Table S3. IPA results. All the top-listed canonical (metabolic \& signaling) pathways using the Fisher's exact test in the $3 \mathrm{~h}$ (Additional file 1: Table S1) and 21h (Additional file 2: Table S2) moxLDL experiment, respectively. Column A depicts canonical pathway name as tagged in the Ingenuity knowledgebase; column B depicts the Fisher exact test $-\log (\mathrm{P}-$ Value); column $\mathrm{C}$ depicts the statistical threshold; column $\mathrm{D}$ provides the correspondence of the moxLDL differentially expressed genes to each of the individual canonical pathways. Partial information from these tables was plotted as Figures $3 \mathrm{~A}$ and $3 \mathrm{~B}$ in this manuscript.

\section{Abbreviations}

ABCA: ATP-binding cassette (ABC) transporters A; ABCG: ATP-binding cassette (ABC) transporters G; ACAT1: Acetoacetyl CoA thiolase; AP-1: Adaptor protein-1; APOE: Apolipoprotein E; AT: Atherosclerosis; CCL19: CCL20, chemokines: CD: Cluster of differentiation; CDH: Cadherin; CDKN1B: Cyclin-dependent kinase inhibitor B; CSF: Colony stimulating factor; CXCL: Chemokine CXC motif, ligand; EGF: Epidermal growth factor; FGF: Fibroblast growth factor; FAK: Focal adhesion kinase; GPCR: GTP-binding protein (G-protein)-coupled receptor; GPR: G-protein coupled receptor; GSEA: Gene Set Enrichment Analysis; HBP1: High density lipoprotein-binding protein 1; HGF: Hepatic growth factor; HMGCS1: 3-hydroxy-3-methylglutarylCoA synthetase 1; HMGCR: HMG-CoA reductase; ID2: Inhibitor of DNA binding-2; IDI1: Isopentenyl-diphosphate delta-isomerase 1; IFNY: Interferon $\gamma$; IGF: Insulin-like growth factor; IL: Interleukin; IL1a: Interleukin 1a; INSIG1: Insulin-induced gene 1; INSIG2: Insulin-induced gene 2; IPA: Ingenuity pathway analysis; IPKB: Ingenuity pathways knowledge base; IRF: Interferon regulatory factor; LDLR: Low density lipoprotein receptor; PKC: Protein
kinase-C; MAPK: Mitogen-activated protein kinase; MCP-1: Monocyte chemotactic protein-1; MD-2: Lymphocyte antigen 96; miR: MicroRNA; MMP: Matrix metalloproteinase; moxLDL: Minimally oxidized LDL; NFkB: Nuclear factor kappa B; NSDHL: NAD(P)H steroid dehydrogenase-like protein; PARD3: Partitioning-defective protein 3; PCDH: Protocadherin; PDGF: Platelet-derived growth factor; PI3K: Phosphatidylinositol 3-kinase: SCAP: SREBP cleavage-activating protein; SMCs: Smooth muscle cells; SREBP: Sterol regulatory element-binding protein; STAT: Signal transducer and activator of transcription; TGF- $\beta$ : Transforming growth factor beta; TLR4: Toll-like receptor 4; VEGF: Vascular endothelial cell growth factor; $(V)$ LDL: (very) low density lipoprotein; VSMC: Vascular smooth muscle cell; ZEB1: Zinc-finger E-Box-binding homeobox 1.

\section{Competing interests}

The authors declare no competing interests.

\section{Authors' contributions}

The project was conceived by JM. Experiments and pathway analyses were performed by GSK, JW, GDB and JM. The obtained results were interpreted by GSK, GDB, JW and JM. The manuscript was written and approved by all authors.

\section{Acknowledgements}

We wish to gratefully acknowledge Dr. Eleftherios P. Diamandis for providing us the opportunity to work with Ingenuity Pathway Analysis. This work was supported by US NIH via National Human Genome Research Institute (NHGRI) [grant number P41HG04118] and by the National Resource for Network Biology [P41 RR031228] to GDB, by the University Health Network and Mount Sinai Hospital, Toronto, Ontario, Canada to EPD and by the Dean's Research Fund, Faculty of Medicine, University of Toronto to JM.

\section{Author details}

'Department of Laboratory Medicine and Pathobiology, Faculty of Medicine, University of Toronto, Toronto, ON M5S 1A8, Canada. ${ }^{2}$ Department of Pathology and Laboratory Medicine, Mount Sinai Hospital, Toronto, ON, Canada. ${ }^{3}$ Department of Molecular Genetics, University of Toronto, Toronto, ON, Canada. ${ }^{4}$ The Donnelly Centre, University of Toronto, Toronto, ON, Canada.

Received: 23 February 2012 Accepted: 29 December 2012 Published: 16 January 2013

\section{References}

1. Ross R: Atherosclerosis-an inflammatory disease. N Engl J Med 1999, 340(2):115-126.

2. Libby P, Ridker PM, Maseri A: Inflammation and atherosclerosis. Circulation 2002, 105(9):1135-1143.

3. Lusis AJ: Atherosclerosis. Nature 2000, 407(6801):233-241

4. Doran AC, Meller N, McNamara CA: Role of smooth muscle cells in the initiation and early progression of atherosclerosis. Arterioscler Thromb Vasc Biol 2008, 28(5):812-819.

5. Tracy RE, Newman WP 3rd, Wattigney WA, Berenson GS: Risk factors and atherosclerosis in youth autopsy findings of the Bogalusa Heart Study. Am J Med Sci 1995, 310(Suppl 1):S37-S41.

6. Berenson GS, Srinivasan SR, Bao W, Newman WP 3rd, Tracy RE, Wattigney WA: Association between multiple cardiovascular risk factors and atherosclerosis in children and young adults. The Bogalusa Heart Study. N Engl J Med 1998, 338(23):1650-1656.

7. Owens GK: Regulation of differentiation of vascular smooth muscle cells. Physiol Rev 1995, 75(3):487-517.

8. Schwartz SM: Smooth muscle migration in atherosclerosis and restenosis. J Clin Invest 1997, 100(11 Suppl):S87-S89.

9. Gittenberger-de Groot AC, DeRuiter MC, Bergwerff M, Poelmann RE: Smooth muscle cell origin and its relation to heterogeneity in development and disease. Arterioscler Thromb Vasc Biol 1999, 19(7):1589-1594.

10. Goldstein JL, Brown MS: The low-density lipoprotein pathway and its relation to atherosclerosis. Annu Rev Biochem 1977, 46:897-930.

11. Navab M, Ananthramaiah GM, Reddy ST, Van Lenten BJ, Ansell BJ, Fonarow GC, Vahabzadeh K, Hama S, Hough G, Kamranpour N, et al: The oxidation hypothesis of atherogenesis: the role of oxidized phospholipids and HDL. J Lipid Res 2004, 45(6):993-1007. 
12. Harkewicz R, Hartvigsen K, Almazan F, Dennis EA, Witztum JL, Miller YI: Cholesteryl ester hydroperoxides are biologically active components of minimally oxidized low density lipoprotein. J Biol Chem 2008, 283 (16):10241-10251.

13. Cathcart MK, Folcik VA: Lipoxygenases and atherosclerosis: protection versus pathogenesis. Free Radic Biol Med 2000, 28(12):1726-1734.

14. Fan J, Watanabe T: Inflammatory reactions in the pathogenesis of atherosclerosis. J Atheroscler Thromb 2003, 10(2):63-71.

15. Virella G, Lopes-Virella MF: Atherogenesis and the humoral immune response to modified lipoproteins. Atherosclerosis 2008, 200(2):239-246.

16. Loppnow H, Werdan K, Buerke M: Vascular cells contribute to atherosclerosis by cytokine- and innate-immunity-related inflammatory mechanisms. Innate Immun 2008, 14(2):63-87.

17. Louis H, Lacolley P, Kakou A, Cattan V, Daret D, Safar M, Bonnet J, Daniel Lamaziere JM: Early activation of internal medial smooth muscle cells in the rabbit aorta after mechanical injury: relationship with intimal thickening and pharmacological applications. Clin Exp Pharmacol Physiol 2006, 33(1-2):131-138.

18. Raines EW, Ferri N: Thematic review series: The immune system and atherogenesis. Cytokines affecting endothelial and smooth muscle cells in vascular disease. J Lipid Res 2005, 46(6):1081-1092.

19. Massaeli H, Hurtado C, Austria JA, Pierce GN: Oxidized low-density lipoprotein induces cytoskeletal disorganization in smooth muscle cells. Am J Physiol 1999, 277(5 Pt 2):H2017-H2025.

20. Robenek $\mathrm{H}$, Severs $\mathrm{NJ}$ : Lipoprotein receptors on macrophages and smooth muscle cells. Curr Top Pathol 1993, 87:73-123.

21. Berk BC: Vascular smooth muscle growth: autocrine growth mechanisms. Physiol Rev 2001, 81(3):999-1030.

22. Zhan Y, Kim S, Izumi Y, Izumiya Y, Nakao T, Miyazaki H, Iwao H: Role of JNK, p38, and ERK in platelet-derived growth factor-induced vascular proliferation, migration, and gene expression. Arterioscler Thromb Vasc Biol 2003, 23(5):795-801.

23. Lien SC, Usami S, Chien S, Chiu JJ: Phosphatidylinositol 3-kinase/Akt pathway is involved in transforming growth factor-beta1-induced phenotypic modulation of 10T1/2 cells to smooth muscle cells. Cell Signal 2006, 18(8):1270-1278

24. Tabibiazar R, Wagner RA, Ashley EA, King JY, Ferrara R, Spin JM, Sanan DA Narasimhan B, Tibshirani R, Tsao PS, et al: Signature patterns of gene expression in mouse atherosclerosis and their correlation to human coronary disease. Physiol Genomics 2005, 22(2):213-226.

25. King JY, Ferrara R, Tabibiazar R, Spin JM, Chen MM, Kuchinsky A, Vailaya A, Kincaid R, Tsalenko A, Deng DX, et al: Pathway analysis of coronary atherosclerosis. Physiol Genomics 2005, 23(1):103-118.

26. Ashley EA, Ferrara R, King JY, Vailaya A, Kuchinsky A, He X, Byers B, Gerckens $U$, Oblin S, Tsalenko A, et al: Network analysis of human in-stent restenosis. Circulation 2006, 114(24):2644-2654.

27. Skogsberg J, Lundstrom J, Kovacs A, Nilsson R, Noori P, Maleki S, Kohler M, Hamsten A, Tegner J, Bjorkegren J: Transcriptional profiling uncovers a network of cholesterol- responsive atherosclerosis target genes. PLOS Genet 2008, 4(3):e1000036.

28. Cagnin S, Biscuola M, Patuzzo C, Trabetti E, Pasquali A, Laveder P, Faggian G, lafrancesco M, Mazzucco A, Pignatti PF, et al: Reconstruction and functional analysis of altered molecular pathways in human atherosclerotic arteries. BMC Genomics 2009, 10:13.

29. Diez M, Musri MM, Ferrer E, Barbera JA, Peinado VI: Endothelial progenitor cells undergo an endothelial-to-mesenchymal transition-like process mediated by TGFbetaRI. Cardiovasc Res 2011, 88(3):502-511.

30. Wheelock CE, Wheelock AM, Kawashima S, Diez D, Kanehisa M, van Erk M, Kleemann R, Haeggstrom JZ, Goto S: Systems biology approaches and pathway tools for investigating cardiovascular disease. Mol Biosyst 2009, 5 (6):588-602.

31. Gargalovic PS, Imura M, Zhang B, Gharavi NM, Clark MJ, Pagnon J, Yang WP, He A, Truong A, Patel S, et al: Identification of inflammatory gene modules based on variations of human endothelial cell responses to oxidized lipids. Proc Natl Acad Sci USA 2006, 103(34):12741-12746.

32. Minta JO, Yun JJ, Kabiawu O, Jones J: mRNA differential display identification of vascular smooth muscle early response genes regulated by PDGF. Mol Cell Biochem 2006, 281(1-2):63-75.

33. Subramanian A, Tamayo P, Mootha VK, Mukherjee S, Ebert BL, Gillette MA, Paulovich A, Pomeroy SL, Golub TR, Lander ES, et al: Gene set enrichment analysis: a knowledge-based approach for interpreting genome-wide expression profiles. Proc Natl Acad Sci USA 2005, 102(43):15545-15550.
34. Merico D, Isserlin R, Stueker O, Emili A, Bader GD: Enrichment map: a network-based method for gene-set enrichment visualization and interpretation. PLoS One 2011, 5(11):e13984

35. Gautier L, Cope L, Bolstad BM, Irizarry RA: affy-analysis of Affymetrix GeneChip data at the probe level. Bioinformatics (Oxford, England) 2004, 20(3):307-315

36. Irizarry RA, Hobbs B, Collin F, Beazer-Barclay YD, Antonellis KJ, Scherf U, Speed TP: Exploration, normalization, and summaries of high density oligonucleotide array probe level data. Biostatistics (Oxford, England) 2003, 4(2):249-264.

37. Isserlin R, Merico D, Alikhani-Koupaei R, Gramolini A, Bader GD, Emili A: Pathway analysis of dilated cardiomyopathy using global proteomic profiling and enrichment maps. Proteomics 2011, 10(6):1316-1327.

38. Ashburner M, Ball CA, Blake JA, Botstein D, Butler H, Cherry JM, Davis AP, Dolinski K, Dwight SS, Eppig JT, et al: Gene ontology: tool for the unification of biology. The Gene Ontology Consortium. Nat Genet 2000, 25(1):25-29.

39. Romero P, Wagg J, Green ML, Kaiser D, Krummenacker M, Karp PD: Computational prediction of human metabolic pathways from the complete human genome. Genome Bio/ 2005, 6(1):R2.

40. Kanehisa M, Goto S, Kawashima S, Nakaya A: The KEGG databases at GenomeNet. Nucleic Acids Res 2002, 30(1):42-46.

41. Schaefer CF, Anthony K, Krupa S, Buchoff J, Day M, Hannay T, Buetow KH: PID: the Pathway Interaction Database. Nucleic Acids Res 2009, 37(Database issue): D674-D679.

42. Kandasamy K, Mohan SS, Raju R, Keerthikumar S, Kumar GS, Venugopal AK, Telikicherla D, Navarro JD, Mathivanan S, Pecquet C, et al: NetPath: a public resource of curated signal transduction pathways. Genome Biol 2011, 11(1):R3-R37.

43. Matthews L, Gopinath G, Gillespie M, Caudy M, Croft D, De Bono B, Garapati $P$, Hemish J, Hermjakob H, Jassal B, et al: Reactome knowledgebase of human biological pathways and processes. Nucleic Acids Res 2009, 37(Database issue):D619-D622.

44. Warde-Farley D, Donaldson SL, Comes O, Zuberi K, Badrawi R, Chao P, Franz M, Grouios C, Kazi F, Lopes CT, et al: The GeneMANIA prediction server: biological network integration for gene prioritization and predicting gene function. Nucleic Acids Res, 38(Web Server issue):W214-W220.

45. Prassas I, Karagiannis GS, Batruch I, Dimitromanolakis A, Datti A, Diamandis EP: Digitoxin- Induced Cytotoxicity in Cancer Cells Is Mediated through Distinct Kinase and Interferon Signaling Networks. Mol Cancer Ther 2011 10(11):2083-2093.

46. Sever N, Yang T, Brown MS, Goldstein JL, DeBose-Boyd RA: Accelerated degradation of HMG CoA reductase mediated by binding of insig-1 to its sterol-sensing domain. Mol Cell 2003, 11(1):25-33.

47. Brown AJ, Sun L, Feramisco JD, Brown MS, Goldstein JL: Cholesterol addition to ER membranes alters conformation of SCAP, the SREBP escort protein that regulates cholesterol metabolism. Mol Cell 2002, 10(2):237-245.

48. Yabe D, Brown MS, Goldstein JL: Insig-2, a second endoplasmic reticulum protein that binds SCAP and blocks export of sterol regulatory elementbinding proteins. Proc Natl Acad Sci USA 2002, 99(20):12753-12758.

49. Radhakrishnan A, Goldstein JL, McDonald JG, Brown MS: Switch-like contro of SREBP-2 transport triggered by small changes in ER cholesterol: a delicate balance. Cell Metab 2008, 8(6):512-521.

50. Nagao S, Murao K, Imachi H, Cao WM, Yu X, Li J, Matsumoto K, Nishiuchi T, Ahmed RA, Wong NC, et al: Platelet derived growth factor regulates ABCA1 expression in vascular smooth muscle cells. FEBS Lett 2006, 580(18):4371-4376.

51. Wang N, Silver DL, Thiele C, Tall AR: ATP-binding cassette transporter A1 (ABCA1) functions as a cholesterol efflux regulatory protein. $J$ Biol Chem 2001, 276(26):23742-23747.

52. Wang N, Lan D, Chen W, Matsuura F, Tall AR: ATP-binding cassette transporters G1 and G4 mediate cellular cholesterol efflux to highdensity lipoproteins. Proc Natl Acad Sci USA 2004, 101(26):9774-9779.

53. Kennedy MA, Barrera GC, Nakamura K, Baldan A, Tarr P, Fishbein MC, Frank J, Francone $\mathrm{OL}$, Edwards PA: ABCG1 has a critical role in mediating cholesterol efflux to HDL and preventing cellular lipid accumulation. Cell Metab 2005, 1(2):121-131.

54. Ogura M, Ayaori M, Terao Y, Hisada T, lizuka M, Takiguchi S, Uto-Kondo H, Yakushiji E, Nakaya K, Sasaki M, et al: Proteasomal inhibition promotes ATP-binding cassette transporter $A 1$ (ABCA1) and ABCG1 expression and cholesterol efflux from macrophages in vitro and in vivo. Arterioscler Thromb Vasc Biol, 31(9):1980-1987. 
55. Gelissen IC, Harris M, Rye KA, Quinn C, Brown AJ, Kockx M, Cartland S, Packianathan $M$, Kritharides $L$, Jessup $W$ : ABCA1 and ABCG1 synergize to mediate cholesterol export to apoA-I. Arterioscler Thromb Vasc Biol 2006, 26(3):534-540

56. Fukao T, Yamaguchi S, Orii T, Schutgens RB, Osumi T, Hashimoto T: Identification of three mutant alleles of the gene for mitochondrial acetoacetyl-coenzyme A thiolase. A complete analysis of two generations of a family with 3-ketothiolase deficiency. J Clin Invest 1992, 89(2):474-479.

57. Caldas H, Herman GE: NSDHL, an enzyme involved in cholesterol biosynthesis, traffics through the Golgi and accumulates on ER membranes and on the surface of lipid droplets. Hum Mol Genet 2003, 12(22):2981-2991

58. Garuti R, Jones C, Li WP, Michaely P, Herz J, Gerard RD, Cohen JC, Hobbs HH: The modular adaptor protein autosomal recessive hypercholesterolemia (ARH) promotes low density lipoprotein receptor clustering into clathrincoated pits. J Biol Chem 2005, 280(49):40996-41004.

59. Claudel T, Leibowitz MD, Fievet C, Tailleux A, Wagner B, Repa JJ, Torpier G, Lobaccaro JM, Paterniti JR, Mangelsdorf DJ, et al: Reduction of atherosclerosis in apolipoprotein $\mathrm{E}$ knockout mice by activation of the retinoid X receptor. Proc Natl Acad Sci USA 2001, 98(5):2610-2615.

60. Pollin TI, Damcott CM, Shen H, Ott SH, Shelton J, Horenstein RB, Post W, McLenithan JC, Bielak LF, Peyser PA, et al: A null mutation in human APOC 3 confers a favorable plasma lipid profile and apparent cardioprotection. Science (New York, NY) 2008, 322(5908):1702-1705.

61. Monajemi H, Fontijn RD, Pannekoek H, Horrevoets AJ: The apolipoprotein L gene cluster has emerged recently in evolution and is expressed in human vascular tissue. Genomics 2002, 79(4):539-546.

62. Leopold JA, Walker J, Scribner AW, Voetsch B, Zhang YY, Loscalzo AJ Stanton RC, Loscalzo J: Glucose-6-phosphate dehydrogenase modulates vascular endothelial growth factor- mediated angiogenesis. J Biol Chem 2003, 278(34):32100-32106

63. Sasaguri T, Arima N, Tanimoto A, Shimajiri S, Hamada T, Sasaguri Y: A role for interleukin 4 in production of matrix metalloproteinase 1 by human aortic smooth muscle cells. Atherosclerosis 1998, 138(2):247-253.

64. Chugh A, Ray A, Gupta JB: Squalene epoxidase as hypocholesterolemic drug target revisited. Prog Lipid Res 2003, 42(1):37-50.

65. Miller YI, Choi SH, Fang L, Harkewicz R: Toll-like receptor-4 and lipoprotein accumulation in macrophages. Trends Cardiovasc Med 2009, 19(7):227-232.

66. Miller YI, Viriyakosol S, Worrall DS, Boullier A, Butler S, Witztum JL: Toll-like receptor 4- dependent and -independent cytokine secretion induced by minimally oxidized low-density lipoprotein in macrophages. Arterioscler Thromb Vasc Biol 2005, 25(6):1213-1219.

67. Maziere C, Auclair M, Djavaheri-Mergny M, Packer L, Maziere JC: Oxidized low density lipoprotein induces activation of the transcription factor NF kappa B in fibroblasts, endothelial and smooth muscle cells. Biochem Mol Biol Int 1996, 39(6):1201-1207.

68. Maziere C, Alimardani G, Dantin F, Dubois F, Conte MA, Maziere JC: Oxidized LDL activates STAT1 and STAT3 transcription factors: possible involvement of reactive oxygen species. FEBS Lett 1999, 448(1):49-52.

69. Maziere C, Conte MA, Maziere JC: Activation of JAK2 by the oxidative stress generated with oxidized low-density lipoprotein. Free Radic Biol Med 2001, 31(11):1334-1340.

70. Chai YC, Howe PH, DiCorleto PE, Chisolm GM: Oxidized low density lipoprotein and lysophosphatidylcholine stimulate cell cycle entry in vascular smooth muscle cells. Evidence for release of fibroblast growth factor-2. J Biol Chem 1996, 271(30):17791-17797.

71. Ananyeva NM, Tjurmin AV, Berliner JA, Chisolm GM, Liau G, Winkles JA Haudenschild CC: Oxidized LDL mediates the release of fibroblast growth factor-1. Arterioscler Thromb Vasc Biol 1997, 17(3):445-453

72. Auge N, Garcia V, Maupas-Schwalm F, Levade T, Salvayre R, Negre-Salvayre A: Oxidized LDL-induced smooth muscle cell proliferation involves the EGF receptor/PI-3 kinase/Akt and the sphingolipid signaling pathways. Arterioscler Thromb Vasc Biol 2002, 22(12):1990-1995.

73. Duan C, Bauchat JR, Hsieh T: Phosphatidylinositol 3-kinase is required for insulin-like growth factor-l-induced vascular smooth muscle cell proliferation and migration. Circ Res 2000, 86(1):15-23.

74. Adam PJ, Clesham GJ, Flynn PD, Weissberg PL: Identification and characterisation of transforming growth factor beta-regulated vascular smooth muscle cell genes. Cytokine 2000, 12(4):348-354

75. Yang CM, Chien CS, Hsiao LD, Pan SL, Wang CC, Chiu CT, Lin CC: Mitogenic effect of oxidized low-density lipoprotein on vascular smooth muscle cells mediated by activation of Ras/Raf/MEK/MAPK pathway. Br J Pharmacol 2001, 132(7):1531-1541.

76. Escargueil-Blanc I, Salvayre R, Vacaresse N, Jurgens G, Darblade B, Arnal JF, Parthasarathy S, Negre-Salvayre A: Mildly oxidized LDL induces activation of platelet-derived growth factor beta-receptor pathway. Circulation 2001, 104(15):1814-1821.

77. Gerthoffer WT: Mechanisms of vascular smooth muscle cell migration. Circ Res 2007, 100(5):607-621.

78. Sanada F, Taniyama Y, lekushi K, Azuma J, Okayama K, Kusunoki H, Koibuchi N, Doi T, Aizawa Y, Morishita R: Negative action of hepatocyte growth factor/c-Met system on angiotensin II signaling via ligand-dependent epithelial growth factor receptor degradation mechanism in vascular smooth muscle cells. Circ Res 2009, 105(7):667-675. 613 p following 675

79. Geng Y, Hansson GK, Holme E: Interferon-gamma and tumor necrosis factor synergize to induce nitric oxide production and inhibit mitochondrial respiration in vascular smooth muscle cells. Circ Res 1992, 71(5):1268-1276.

80. Barath P, Fishbein MC, Cao J, Berenson J, Helfant RH, Forrester JS: Detection and localization of tumor necrosis factor in human atheroma. Am J Cardiol 1990, 65(5):297-302

81. Vickers KC, Remaley AT: MicroRNAs in atherosclerosis and lipoprotein metabolism. Curr Opin Endocrinol Diabetes Obes, 17(2):150-155.

82. Schroen B, Heymans S: Small but smart - microRNAs in the center of inflammatory processes during cardiovascular diseases, the metabolic syndrome and aging. Cardiovasc Res 2011

83. Goetze $\mathrm{S}, \mathrm{Xi}$ XP, Kawano Y, Kawano H, Fleck E, Hsueh WA, Law RE: TNF-alpha-induced migration of vascular smooth muscle cells is MAPK dependent. Hypertension 1999, 33(1 Pt 2):183-189.

84. Ortiz-Munoz G, Martin-Ventura JL, Hernandez-Vargas P, Mallavia B, Lopez-Parra V, Lopez-Franco O, Munoz-Garcia B, Fernandez-Vizarra P, Ortega L, Egido J, et al: Suppressors of cytokine signaling modulate JAK/STAT-mediated cell responses during atherosclerosis. Arterioscler Thromb Vasc Biol 2009, 29(4):525-531.

85. Hirai H, Kanaya R, Maeda M, Qungfang D, Ina K, Hayashi T: The role of insulin growth factor on atherosclerosis and endothelial function: the effect on hyperlipidemia and aging. Life Sci 2011, 88(9-10):425-431.

86. Young HA, Bream JH: IFN-gamma: recent advances in understanding regulation of expression, biological functions, and clinical applications. Curr Top Microbiol Immunol 2007, 316:97-117.

87. Horwitz AR, Parsons JT: Cell migration-movin' on. Science (New York, NY) 1999, 286(5442):1102-1103.

88. Smilenov LB, Mikhailov A, Pelham RJ, Marcantonio EE, Gundersen GG: Focal adhesion motility revealed in stationary fibroblasts. Science (New York, NY 1999, 286(5442):1172-1174.

89. Willis Al, Pierre-Paul D, Sumpio BE, Gahtan V: Vascular smooth muscle cell migration: current research and clinical implications. Vasc Endovascular Surg 2004, 38(1):11-23

90. Hiroki J, Shimokawa H, Higashi M, Morikawa K, Kandabashi T, Kawamura N, Kubota T, Ichiki T, Amano M, Kaibuchi K, et al: Inflammatory stimuli upregulate Rho-kinase in human coronary vascular smooth muscle cells. J Mol Cell Cardiol 2004, 37(2):537-546.

91. Rudijanto A: The role of vascular smooth muscle cells on the pathogenesis of atherosclerosis. Acta Med Indones 2007, 39(2):86-93.

92. Aidoudi S, Bikfalvi A: Interaction of PF4 (CXCL4) with the vasculature: a role in atherosclerosis and angiogenesis. Thromb Haemost 2011, 104(5):941-948

93. Wang Z, Newman WH: Smooth muscle cell migration stimulated by interleukin 6 is associated with cytoskeletal reorganization. J Surg Res 2003, 111(2):261-266.

94. Lim CS, Shalhoub J, Gohel MS, Shepherd AC, Davies AH: Matrix metalloproteinases in vascular disease-a potential therapeutic target? Curr Vasc Pharmacol 2011, 8(1):75-85.

95. Pace U, Lancet D: Olfactory GTP-binding protein: signal-transducing polypeptide of vertebrate chemosensory neurons. Proc Natl Acad Sci USA 1986, 83(13):4947-4951

96. Spehr M, Munger SD: Olfactory receptors: G protein-coupled receptors and beyond. J Neurochem 2009, 109(6):1570-1583.

97. Uglow EB, Slater S, Sala-Newby GB, Aguilera-Garcia CM, Angelini GD, Newby AC, George SJ: Dismantling of cadherin-mediated cell-cell contacts modulates smooth muscle cell proliferation. Circ Res 2003, 92(12):1314-1321.

98. Dwivedi A, Slater SC, George SJ: MMP-9 and -12 cause N-cadherin shedding and thereby beta-catenin signalling and vascular smooth muscle cell proliferation. Cardiovasc Res 2009, 81(1):178-186. 
99. George SJ, Beeching CA: Cadherin:catenin complex: a novel regulator of vascular smooth muscle cell behaviour. Atherosclerosis 2006, 188(1):1-11.

100. George SJ, Dwivedi A: MMPs, cadherins, and cell proliferation. Trends Cardiovasc Med 2004, 14(3):100-105.

101. Hulpiau P, van Roy F: Molecular evolution of the cadherin superfamily. Int J Biochem Cell Biol 2009, 41(2):349-369.

102. Wells A, Chao YL, Grahovac J, Wu Q, Lauffenburger DA: Epithelial and mesenchymal phenotypic switchings modulate cell motility in metastasis. Front Biosci 2011, 16:815-837.

103. Walker MM, Ellis SM, Auza MJ, Patel A, Clark P: The intercellular adhesion molecule, cadherin-10, is a marker for human prostate luminal epithelial cells that is not expressed in prostate cancer. Mod Pathol 2008, 21(2):85-95.

104. Liu Q, Chen Y, Pan JJ, Murakami T: Expression of protocadherin-9 and protocadherin-17 in the nervous system of the embryonic zebrafish. Gene Expr Patterns 2009, 9(7):490-496.

105. Indig FE, Diaz-Gonzalez F, Ginsberg MH: Analysis of the tetraspanin CD9integrin alphallbbeta3 (GPIllb-Illa) complex in platelet membranes and transfected cells. Biochem J 1997, 327(Pt 1):291-298.

106. Takeda Y, Li Q, Kazarov AR, Epardaud M, Elpek K, Turley SJ, Hemler ME: Diminished metastasis in tetraspanin CD151-knockout mice. Blood 2011, 118(2):464-472.

107. Hidalgo-Carcedo C, Hooper S, Chaudhry SI, Williamson P, Harrington K, Leitinger B, Sahai E: Collective cell migration requires suppression of actomyosin at cell-cell contacts mediated by DDR1 and the cell polarity regulators Par3 and Par6. Nat Cell Biol 2011, 13(1):49-58.

108. Zhivotovsky B, Orrenius S: Cell cycle and cell death in disease: past, present and future. J Intern Med 2011, 268(5):395-409.

109. Sampson EM, Haque ZK, Ku MC, Tevosian SG, Albanese C, Pestell RG, Paulson KE, Yee AS: Negative regulation of the Wnt-beta-catenin pathway by the transcriptional repressor HBP1. EMBO J 2001, 20(16):4500-4511.

110. Hara E, Yamaguchi T, Nojima H, Ide T, Campisi J, Okayama H, Oda K. Id-related genes encoding helix-loop-helix proteins are required for $\mathrm{G} 1$ progression and are repressed in senescent human fibroblasts. J Biol Chem 1994, 269(3):2139-2145.

111. Zhu X, Lin Y, Bacanamwo M, Chang L, Chai R, Massud I, Zhang J, GarciaBarrio MT, Thompson WE, Chen YE: Interleukin-1 beta-induced Id2 gene expression is mediated by Egr-1 in vascular smooth muscle cells. Cardiovasc Res 2007, 76(1):141-148.

112. Damiani E, Sugiyama T, Shimamura K, Greci L, Matsuda Y: Altered expression of alpha-actin, smooth muscle myosin heavy chain-1 and calponin in cultured smooth muscle cells by oxidized low density lipoproteins. FEBS Lett 1998, 425(1):123-125.

113. Weissberg PL, Cary NR, Shanahan CM: Gene expression and vascular smooth muscle cell phenotype. Blood Press 1995, 2:68-73.

doi:10.1186/1471-2261-13-4

Cite this article as: Karagiannis et al:: Integrative pathway dissection of molecular mechanisms of moxLDL-induced vascular smooth muscle phenotype transformation. BMC Cardiovascular Disorders 2013 13:4.

\section{Submit your next manuscript to BioMed Central and take full advantage of:}

- Convenient online submission

- Thorough peer review

- No space constraints or color figure charges

- Immediate publication on acceptance

- Inclusion in PubMed, CAS, Scopus and Google Scholar

- Research which is freely available for redistribution

Submit your manuscript at www.biomedcentral.com/submit
Ciomed Central 